\title{
Will a Warmer World Mean a Wetter or Drier Australian Monsoon? 0
}

\author{
Josephine R. Brown, Aurel F. Moise, Robert Colman, and Huqiang Zhang \\ Bureau of Meteorology, Melbourne, Victoria, Australia
}

(Manuscript received 1 October 2015, in final form 7 March 2016)

\begin{abstract}
Multimodel mean projections of the Australian summer monsoon show little change in precipitation in a future warmer climate, even under the highest emission scenario. However, there is large uncertainty in this projection, with model projections ranging from around a $40 \%$ increase to a $40 \%$ decrease in summer monsoon precipitation. To understand the source of this model uncertainty, a set of 33 climate models from the Coupled Model Intercomparison Project phase 5 (CMIP5) is divided into groups based on their future precipitation projections (DRY, MID, and WET terciles). The DRY model mean has enhanced sea surface temperature (SST) warming across the equatorial Pacific, with maximum increases in precipitation in the western equatorial Pacific. The DRY model mean also has a large cold bias in present day SSTs in this region. The WET model mean has the largest warming in the central and eastern equatorial Pacific, with precipitation increases over much of Australia. These results suggest lower confidence for projections of reduced monsoon precipitation because of the influence of model SST biases on the SST warming pattern and precipitation response. The precipitation changes for the DRY and WET models are also decomposed into dynamic and thermodynamic components. The component due to spatial shifts in the location of convergence and precipitation is responsible for most of the difference between DRY and WET models. As spatial shifts in precipitation are closely associated with patterns of SST change, reducing uncertainty in model SST warming patterns will be crucial to improved projections of Australian monsoon precipitation.
\end{abstract}

\section{Introduction}

Recent studies have found that global monsoon precipitation is likely to strengthen over the twenty-first century, with both increased intensity and area (Wang et al. 2012; Christensen et al. 2013; Hsu et al. 2013; Kitoh et al. 2013; Lee and Wang 2014). In part, this is because higher temperatures are expected to increase available moisture, and hence precipitation, despite anticipated general weakening of the tropical circulation (Held and Soden 2006; Vecchi et al. 2006). Consistent with this, the latest climate model projections show a consensus of moistening of the South Asian and East Asian monsoons (Christensen et al. 2013). Projections for the Australian component of the Asian-Australian monsoon system, however, are much less certain. A recent model assessment

Supplemental information related to this paper is available at the Journals Online website: http://dx.doi.org/10.1175/JCLI-D-15-0695.s1.

Corresponding author address: Josephine R. Brown, Bureau of Meteorology, 700 Collins St., Melbourne VIC 3000, Australia. E-mail: j.brown@bom.gov.au study concluded that Australian monsoon precipitation changes will likely be a small increase, but also indicated low confidence because of the wide model spread (Christensen et al. 2013). Moreover, shared biases in models mean that even this spread may not encompass the true changes and imply that simple ensemble averaging is likely to be inappropriate (e.g., Moise et al. 2012; Grose et al. 2014a; Zhang et al. 2016).

A number of factors contribute to the uncertainty in Australian monsoon precipitation projections. The Australian monsoon is characterized by extremely high variability on all time scales, including intraseasonal and interannual (e.g., Drosdowsky 1996). Hemispheric asymmetries in global warming, which are expected to reinforce Northern Hemisphere $(\mathrm{NH})$ monsoons through enhanced land-ocean temperature contrasts, play an uncertain role in the Southern Hemisphere (SH; Wang et al. 2012; Lee and Wang 2014). The Australian monsoon is very strongly modulated by Pacific sea surface temperature (SST) changes, and in particular El Niño-Southern Oscillation (ENSO) events (e.g., Drosdowsky 1996; Smith et al. 2008; Zhang 2010), and projected changes in ENSO are uncertain (Collins et al. 2010). Critically too, models 
are subject to significant and persistent biases in equatorial Pacific SSTs, which may have a large influence on their ability to simulate both current and future climates (e.g., Xie et al. 2010; J. N. Brown et al. 2013; Li and Xie 2014; Grose et al. 2014a,b).

Previous studies have investigated the range of monsoon projections from coupled climate models from both phase 3 of the Coupled Model Intercomparison Project (CMIP3; Meehl et al. 2007) and phase 5 (CMIP5; Taylor et al. 2012). Moise et al. (2012) considered projections of Australian monsoon precipitation in CMIP3 simulations of future climate from 19 models. No significant change in summer monsoon precipitation over northern Australia was identified under the A2 emission scenario, with a large spread in model projections. The CMIP5 ensemble 12 "best models" of Jourdain et al. (2013) simulated a 5\%-20\% increase in Australian summer monsoon precipitation in the second half of the twenty-first century under the RCP8.5 emission scenario compared with the preindustrial period. Another study of CMIP5 models under the RCP4.5 scenario found that Australian summer monsoon precipitation increased by $2.6 \%{ }^{\circ} \mathrm{C}^{-1}$ of warming by the end of the twenty-first century, which was less than the Indian or East Asian components of the Asian summer monsoon (Wang et al. 2014). This study found that the relatively greater warming in the $\mathrm{NH}$ than the $\mathrm{SH}$ favors the Asian summer monsoon but reduces enhancement of the Australian summer monsoon precipitation. An increase of "monsoonality" (ratio of summer precipitation to annual precipitation) was also identified for the Australian monsoon (Wang et al. 2014).

One reason for the relatively small and uncertain projected changes in mean Australian monsoon precipitation is that the changes represent the sum of opposing dynamic and thermodynamic processes (e.g., Held and Soden 2006; Chou et al. 2009; Seager et al. 2010). A recent study (Endo and Kitoh 2014) decomposed changes for regional monsoons and found that the Australian monsoon experiences an increase in precipitation due to thermodynamic processes (wet get wetter), but a similar magnitude decrease due to dynamic processes where relatively greater warming elsewhere leads to less precipitation over the monsoon domain (warmer get wetter), with smaller additional changes due to evaporation (positive) and transient eddies (negative). The smaller contribution of the (negative) dynamic term over the Asian monsoon region, in contrast, leads to greater increases in Asian monsoon precipitation (Endo and Kitoh 2014).

The aim of this study is to examine the Australian monsoon projections from the CMIP5 models to address the question of why there is such a large model spread in precipitation projections, and whether some model projections may be considered more plausible. A major aim is to explore and understand the physical processes underlying the range of model projections. To examine these processes, the models are grouped according to their projected monsoon precipitation change. The changes for all models and for each group are also decomposed into dynamic and thermodynamic components to provide further insight into the mechanisms behind the changes.

The structure of the paper is as follows. In section 2 the data and models and the decomposition method are introduced. In section 3 the simulation of the Australian monsoon is evaluated for the entire CMIP5 ensemble, and projected changes are presented. The impacts of changes in regional SSTs, land-ocean temperature contrasts, and interhemispheric temperature gradients on monsoon precipitation changes are also evaluated. In section 4 the monsoon precipitation projections are analyzed for different subgroups of models, and in section 5 precipitation changes are decomposed following the method of Chadwick et al. (2013). Finally, discussion and conclusions are given in section 6.

\section{Data, models, and methods}

\section{a. Data and models}

The Australian Water Availability Project (AWAP) precipitation dataset (Jones et al. 2009) at $0.25^{\circ}$ resolution was used to calculate average precipitation over the Australian monsoon domain, defined here as the land areas bounded by $10^{\circ}-20^{\circ} \mathrm{S}, 120^{\circ}-150^{\circ} \mathrm{E}$. Global gridded precipitation observations were taken from the Climate Prediction Center Merged Analysis of Precipitation (CMAP; Xie and Arkin 1997) and Global Precipitation Climatology Project (GPCP) version 2 (Adler et al. 2003) datasets. SST data were obtained from the HadISST dataset (Rayner et al. 2003). Observed winds were taken from the NCEP-DOE Reanalysis II (NCEP-2; Kanamitsu et al. 2002) and the ERA-40 reanalysis (Uppala et al. 2005).

A set of 33 CMIP5 coupled atmosphere-ocean climate models (Taylor et al. 2012) was used in this study (see Table 1). For each model, simulations of "Historical" climate and the climate of the twenty-first century under the RCP8.5 emission scenario were analyzed. Further details of the CMIP5 models and experimental design are available online (http://cmip-pcmdi.llnl.gov/ cmip5/). The Historical simulations were forced by prescribed changes in solar input, volcanoes, and land use as well as greenhouse gases and aerosols to simulate the climate of the period 1850-2005 (Taylor et al. 2012). The RCP8.5 simulations use projected greenhouse gas, aerosol, and land use change forcing to simulate climate 
TABLE 1. CMIP5 models included in this study. Information summarized from CMIP5 website (http://cmip-pcmdi.llnl.gov/cmip5/ availability.html).

\begin{tabular}{|c|c|}
\hline Model name(s) & Model host institution(s) \\
\hline ACCESS1.0 & Commonwealth Scientific and Industrial Research Organisation (CSIRO) and Bureau of Meteorology \\
\hline \multicolumn{2}{|r|}{ נ } \\
\hline BCC_CSM1.1 & Beijing Climate Center, China Meteorological Administration \\
\hline BNU-ESM & College of Global Change and Earth System Science, Beijing Normal University \\
\hline CanESM2 & Canadian Centre for Climate Modelling and Analysis \\
\hline CCSM4 & National Center for Atmospheric Research \\
\hline CESM1(BGC) & National Science Foundation, Department of Energy, National Center for Atmospheric Research \\
\hline \multicolumn{2}{|l|}{ CESM1(CAM5) } \\
\hline CMCC-CESM & Centro Euro-Mediterraneo per i Cambiamenti Climatici \\
\hline \multicolumn{2}{|r|}{ - } \\
\hline CNRM-CM5 & $\begin{array}{l}\text { Centre National de Recherches Météorologiques/Centre Européen de Recherche et Formation } \\
\text { Avancée en Calcul Scientifique }\end{array}$ \\
\hline CSIRO Mk3.6.0 & CSIRO \\
\hline FGOALS-g2 & $\begin{array}{l}\text { LASG, Institute of Atmospheric Physics, Chinese Academy of Sciences, and Center for Earth } \\
\text { System Science, Tsinghua University }\end{array}$ \\
\hline FGOALS-s2 & LASG, Institute of Atmospheric Physics, Chinese Academy of Sciences \\
\hline FIO-ESM & First Institute of Oceanography, State Oceanic Administration, China \\
\hline GFDL CM3 & Geophysical Fluid Dynamics Laboratory \\
\hline \multicolumn{2}{|l|}{ GFDL-ESM2G } \\
\hline \multicolumn{2}{|l|}{ GFDL-ESM2M } \\
\hline GISS-E2-H & NASA Goddard Institute for Space Studies \\
\hline \multicolumn{2}{|l|}{ GISS-E2-R } \\
\hline HadGEM2-AO & National Institute of Meteorological Research/Korea Meteorological Administration \\
\hline HadGEM2-CC & Met Office Hadley Centre \\
\hline \multicolumn{2}{|l|}{ HadGEM2-ES } \\
\hline IPSL-CM5A-LR & L'Institut Pierre-Simon Laplace \\
\hline \multicolumn{2}{|l|}{ IPSL-CM5A-MR } \\
\hline MIROC5 & $\begin{array}{l}\text { Atmosphere and Ocean Research Institute (University of Tokyo), National Institute for } \\
\text { Environmental Studies, and Japan Agency for Marine-Earth Science and Technology }\end{array}$ \\
\hline MIROC-ESM & $\begin{array}{l}\text { Japan Agency for Marine-Earth Science and Technology, Atmosphere and Ocean Research } \\
\text { Institute (The University of Tokyo), and National Institute for Environmental Studies }\end{array}$ \\
\hline \multicolumn{2}{|l|}{ MIROC-ESM-CHEM } \\
\hline MPI-ESM-LR & Max Planck Institute for Meteorology (MPI-M) \\
\hline \multicolumn{2}{|l|}{ MPI-ESM-MR } \\
\hline MRI-CGCM3 & Meteorological Research Institute \\
\hline NorESM1-M & Norwegian Climate Centre \\
\hline NorESM1-ME & \\
\hline
\end{tabular}

from 2006 to 2100. RCP8.5 is a high-emission scenario, with no stabilization of greenhouse gas concentrations during the twenty-first century. For each model, the first realization (run 1) was used for both experiments. The model fields were regridded to a common $1.5^{\circ} \times 1.5^{\circ} \mathrm{grid}$ before further analysis.

\section{b. Decomposition method}

The projected changes in precipitation from the present to future climate were analyzed using the decomposition method of Chadwick et al. (2013). This method is based on the assumption that precipitation $(P)$ in the tropics can be considered a function of mass flux from the boundary layer to free troposphere $(M)$ and boundary layer specific humidity $(q)$, as demonstrated by Chadwick et al. (2013) and Kent et al. (2015).
As the mass flux term cannot be obtained directly from the climate model, a proxy variable $\left(M^{*}\right)$ is used instead:

$$
M^{*}=P / q
$$

The proxy mass flux term has been shown to be closely related to the model convective mass flux in the tropics (Chadwick et al. 2013; Kent et al. 2015). Using this approximation, a change in precipitation (in this case, RCP8.5 minus Historical) can be decomposed at each grid point into five components (we use the terminology adopted by Kent et al. 2015):

$$
\begin{aligned}
\Delta P= & M^{*} \Delta q_{\mathrm{cc}}+M^{*} \Delta q_{\mathrm{rh}}+q \Delta M_{\text {weak }}^{*} \\
& +q \Delta M_{\mathrm{shift}}^{*}+\Delta q \Delta M^{*},
\end{aligned}
$$


where $M^{*}$ is calculated at each grid point from (1), $q$ is the near-surface specific humidity, $\Delta q_{\mathrm{cc}}$ is the change in specific humidity due to the Clausius-Clapeyron relation, $\Delta q_{\mathrm{rh}}=\Delta q-\Delta q_{\mathrm{cc}}$ is the residual due to changes in surface relative humidity, $\Delta M_{\text {weak }}^{*}$ is the change due to the weakening of the atmospheric circulation in the tropics (see Chadwick et al. 2013 for details of calculation of this term), and $\Delta M_{\text {shift }}^{*}=\Delta M^{*}-\Delta M_{\text {weak }}^{*}$ is the change due to spatial shift in patterns of convective mass flux. The decomposition can be rewritten as

$$
\Delta P=\Delta P_{t}+\Delta P_{\text {rh }}+\Delta P_{\text {weak }}+\Delta P_{\text {shift }}+\Delta P_{\text {cross }},
$$

where $\Delta P_{t}$ is the "thermodynamic" change in precipitation, $\Delta P_{\mathrm{rh}}$ is the change due to relative humidity, $\Delta P_{\text {weak }}$ is the change due weakening of the circulation, $\Delta P_{\text {shift }}$ is the change to spatial shifts, and $\Delta P_{\text {cross }}$ is the nonlinear "cross term."

Note that we use the specific humidity at $925 \mathrm{hPa}$ rather than at the surface. This is because of the larger set of models with $925-\mathrm{hPa}$ specific humidity output (all 33 models included in this study) compared to the models with surface specific humidity (22 models) available at the time of this study. The differences in the multimodel mean precipitation terms because of this choice are generally small (not shown).

Chadwick et al. (2013) found that the spatial shift term $\left(\Delta P_{\text {shift }}\right)$ was most important for multimodel mean patterns of annual precipitation change in the tropics, as the thermodynamic and weakening terms largely cancelled. A similar result applies to seasonal mean precipitation over the tropics (Kent et al. 2015). However, this may not be the case for the Australian monsoon region or for individual models. The decomposition of precipitation change is applied here to provide insight into the different mechanisms driving Australian monsoon precipitation changes in the CMIP5 models. Note that there are a range of other methods for decomposing precipitation change into dynamic and thermodynamic components (e.g., Emori and Brown 2005; Held and Soden 2006; Chou et al. 2009; Seager et al. 2010). We use the Chadwick et al. (2013) method here as the inclusion of separate terms for weakening, and spatial shifts in mass flux offers additional information.

\section{Changes in mean monsoon precipitation}

\section{a. Monsoon in historical simulations}

The Historical (1980-2005) climatological seasonal cycles of precipitation and $850-\mathrm{hPa}$ zonal winds in the Australian monsoon domain from the 33 CMIP5 models are shown in Fig. 1. The precipitation seasonal cycle
(Fig. 1a) is calculated over the domain $10^{\circ}-20^{\circ} \mathrm{S}, 120^{\circ}-$ $150^{\circ} \mathrm{E}$ for land points only. The CMIP5 multimodel mean (MMM) and observed precipitation seasonal cycles from CMAP and AWAP precipitation datasets are also shown. The MMM precipitation seasonal cycle lies between the CMAP and AWAP values during December-February peak monsoon months, but overestimates values during March and April, implying a later average monsoon termination than observed. However, the close match between MMM and observations disguises the very large spread between models, from around $50 \%$ less than the MMM to around 50\% more than the MMM during the wet season months. Despite this range, the simulation of the Australian monsoon precipitation seasonal cycle in CMIP5 models is improved compared with CMIP3 models (Colman et al. 2011, Fig. 6), with fewer very poor models in the CMIP5 ensemble. Previous studies have also identified a modest improvement in the simulation of Australian monsoon precipitation seasonality in CMIP5 compared with CMIP3 models (Li et al. 2012; Jourdain et al. 2013).

A distinctive feature of the Australian monsoon onset is a shift from low-level easterlies to westerlies (Drosdowsky 1996). The 850-hPa zonal (westerly) wind seasonal cycle averaged over $5^{\circ}-15^{\circ} \mathrm{S}, 120^{\circ}-150^{\circ} \mathrm{E}$ (land and ocean points) is shown in Fig. 1b for models and ERA-40 and NCEP-2 reanalyses (ERA-40 data for 1980-2001 only). The simulation of the zonal wind seasonal cycle in CMIP5 models is also somewhat improved compared with CMIP3 models (cf. Colman et al. 2011, Fig. 3). A large majority of CMIP5 models capture the seasonal reversal of wind direction during the NovemberApril wet season, although the wind reversal is typically 1-2 months too late in the models compared with observations. A subset of models fails to simulate the seasonal wind reversal over the Australian monsoon domain. This implies that these models fail to simulate the classically defined monsoon onset (Drosdowsky 1996), or at least do not capture the southern extent of the monsoon circulation, as was found for a subset of CMIP3 (Zhang et al. 2013) and CMIP5 (Zhang et al. 2016) models.

The biases in model mean SST and precipitation are also examined. December-February (DJF) mean CMIP5 MMM SSTs are compared with HadISST observations for the period 1980-2005, shown in Supplementary Fig. 1a. The CMIP5 MMM displays a cold bias in the equatorial Pacific "cold tongue" region, with a large cool anomaly near the date line, a feature identified in numerous previous evaluations of CMIP5 models (e.g., Li and Xie 2014; Grose et al. 2014a). The bias in austral summer (DJF) CMIP5 MMM precipitation is calculated relative to CMAP observations (similar results are obtained if the GPCP dataset is used instead) 
(a) Annual cycle precipitation (1980-2005)

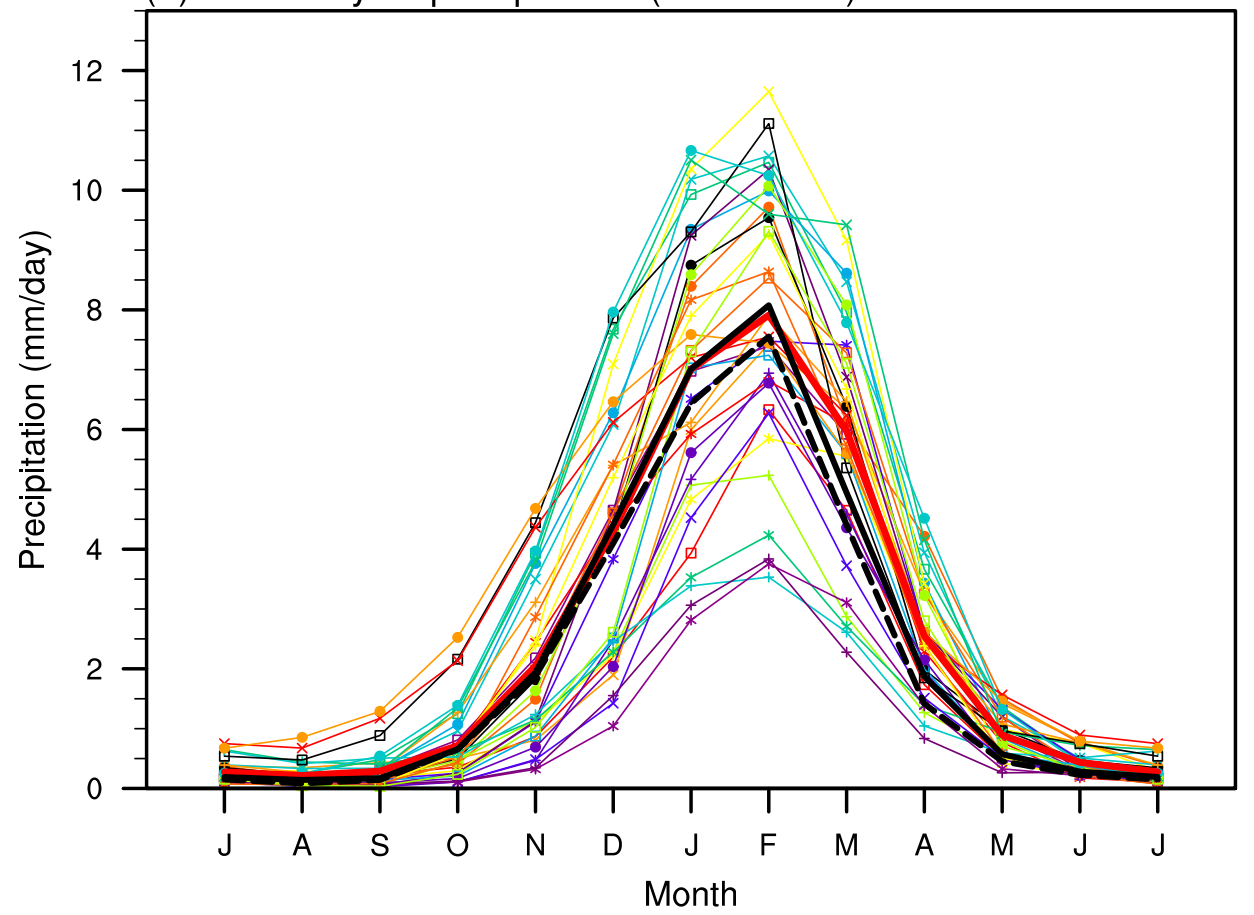

(b) Annual cycle $850 \mathrm{hPa}$ zonal wind (1980-2005)

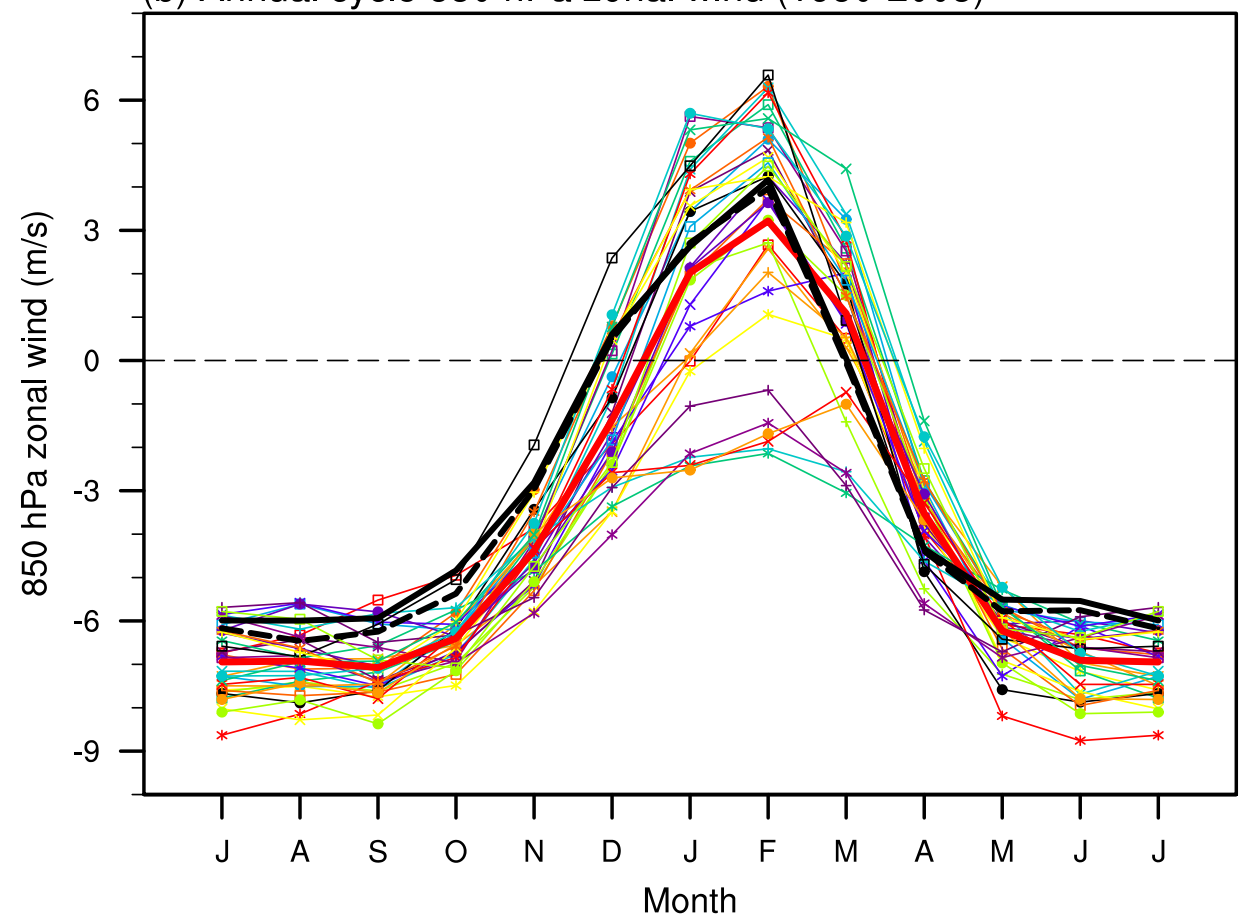

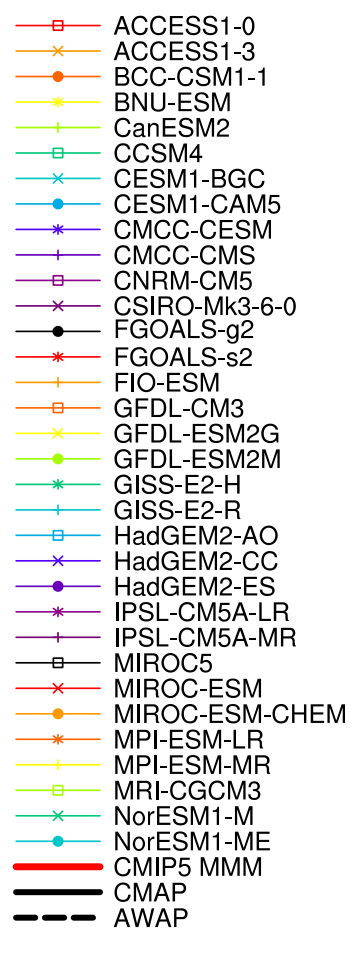

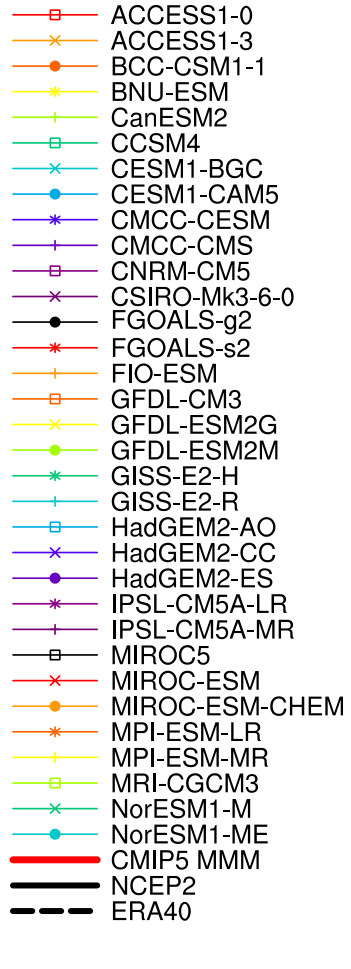

FIG. 1. Historical (1980-2005) climatologies of (a) precipitation averaged over $10^{\circ}-20^{\circ} \mathrm{S}, 120^{\circ}-150^{\circ} \mathrm{E}$ (land only) for CMIP5 models, CMIP5 MMM (thick red line), and CMAP and AWAP observations (thick black solid and dashed lines) and (b) 850-hPa zonal wind averaged over $5^{\circ}-15^{\circ} \mathrm{S}, 120^{\circ}-150^{\circ} \mathrm{E}$ for CMIP5 models, CMIP5 MMM (thick red line), and ERA-40 (for 1980-2001 only) and NCEP-2 observations (thick black solid and dashed lines). 
(a) $\triangle \mathrm{DJF}$ precipitation

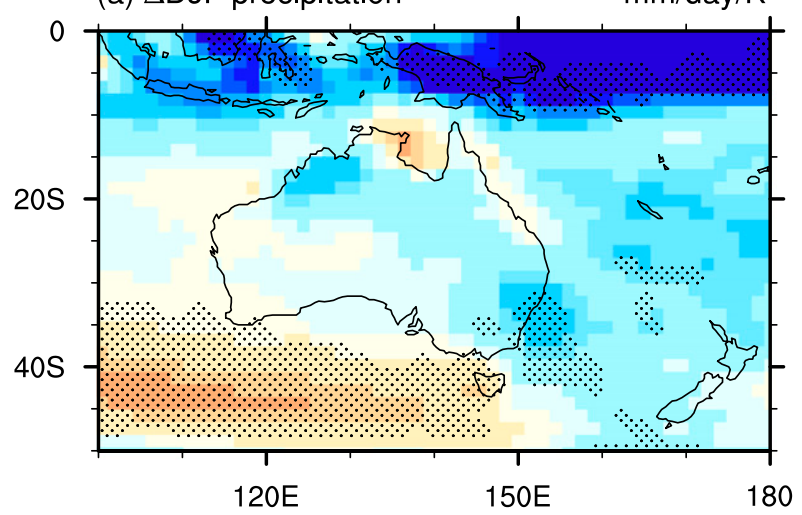

(b) $\triangle \mathrm{DJF} 850 \mathrm{hPa}$ wind

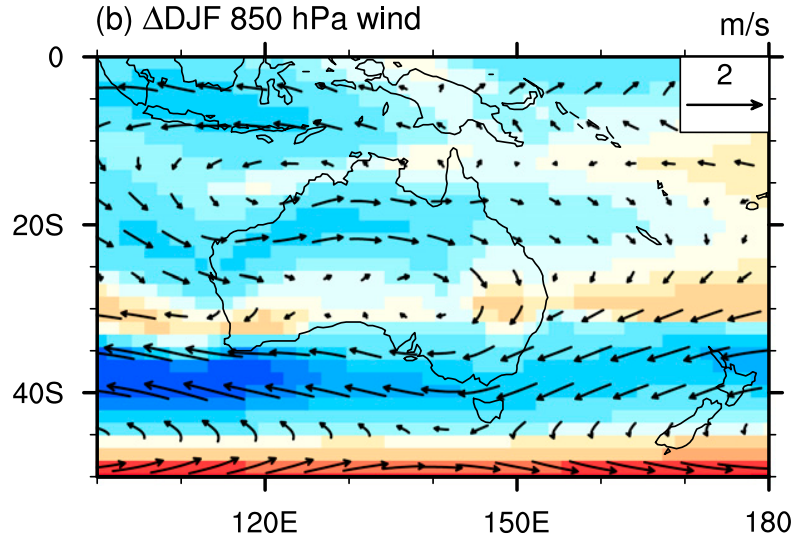

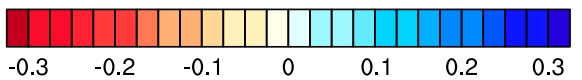

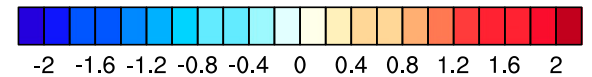

FIG. 2. CMIP5 MMM (a) DJF precipitation change $\left(\mathrm{mm} \mathrm{day}^{-1} \mathrm{~K}^{-1}\right)$ and (b) DJF wind change ( $\mathrm{m} \mathrm{s}^{-1}$ ) for RCP8.5 (2070-99) minus Historical (1970-99). Stippling in (a) indicates regions where more than $80 \%$ of models agree on the sign of the change. Wind vectors in (b) indicate change in wind direction; colors indicate change in wind strength.

for the period 1980-2005, shown in Supplementary Fig. 2a. The MMM precipitation is too low in the western equatorial Pacific, with the largest dry bias to the west of the date line in the region of the large cold MMM SST bias. There is a wet bias farther to the west over the Maritime Continent. Over northern Australia, the MMM precipitation is too low in the northeast and too high in the northwest. Models also simulate too little precipitation in the South Pacific at the eastern edge of the South Pacific convergence zone (SPCZ), as found in previous studies (e.g., J. R. Brown et al. 2013). The intermodel variation of SST and precipitation biases is discussed further in section 4 .

\section{b. Monsoon precipitation changes}

Australian summer monsoon precipitation at the end of the twenty-first century under the RCP8.5 emission scenario is compared with the precipitation at the end of the twentieth century in the Historical simulations. Thirty-year averages are used to reduce the influence of decadal variability on the anomalies. The MMM DJF precipitation change $\left(\mathrm{mm} \mathrm{day}^{-1} \mathrm{~K}^{-1}\right)$ from $1970-9$ to 2070-99 is shown in Fig. 2a. The precipitation change for each model is normalized by the model's global annual mean surface air temperature change before the MMM is calculated. Stippled areas on the figure indicate regions where more than $80 \%$ of models agree on the sign of the precipitation change. There is a large region of increased precipitation over the western equatorial $\mathrm{Pa}$ cific and New Guinea, but only small changes over northern Australia, with no model agreement on the sign of the change. The MMM precipitation anomaly shows increased precipitation over northwestern Australia and little change over the northeast. The MMM DJF change in 850-hPa winds (Fig. 2b) shows a weakening of monsoon winds over northern Australia and the adjacent ocean region to the north.

While the MMM Australian summer monsoon change is very small, there is a wide intermodel spread of changes in monsoon precipitation for the 33 CMIP5 models examined (see Table 2, Fig. 3). The Australian summer monsoon precipitation change is defined here as the DJF precipitation change $\left(\% \mathrm{~K}^{-1}\right)$ for all land grid points in the domain $10^{\circ}-20^{\circ} \mathrm{S}, 120^{\circ}-150^{\circ} \mathrm{E}$, consistent with Colman et al. (2011) and Moise et al. (2012). The precipitation change is normalized by the global annual average temperature change for each model. Note that the normalized relative precipitation change $\left(\% \mathrm{~K}^{-1}\right)$ is used here to compare models, whereas the normalized absolute change $\left(\mathrm{mmday}{ }^{-1} \mathrm{~K}^{-1}\right)$ is used above and elsewhere to capture spatial patterns and gradients in precipitation change. Out of 33 models, 20 simulate increased DJF monsoon precipitation and 13 simulate a decrease. The average change is $0.4 \% \mathrm{~K}^{-1}$, while the models with the largest increases are BNUESM $\left(8.6 \% \mathrm{~K}^{-1}\right)$ and NorESM1-M $\left(5.9 \% \mathrm{~K}^{-1}\right)$ and the models with the largest decreases are CSIRO Mk3.6.0 $\left(-11.1 \% \mathrm{~K}^{-1}\right)$ and GISS-E2-H $\left(-8.9 \% \mathrm{~K}^{-1}\right)$. The model classification shown in Fig. 3 is discussed in section 4.

A number of factors may control changes in monsoon precipitation in a warming climate. Studies have found that relative changes in SSTs in the tropical Pacific and Indian Ocean have a large impact on Australian precipitation (Watterson 2012). Global and regional monsoon precipitation changes may be associated with changes in the land-ocean temperature contrast, as well 
TABLE 2. CMIP5 model simulated change in DJF Australian summer monsoon precipitation (\% and $\% \mathrm{~K}^{-1}$, normalized by global average temperature change) for RCP8.5 (2070-99) minus Historical (1970-99) and resulting model classification (see text for details). Monsoon precipitation is calculated for land points in the domain $10^{\circ}-20^{\circ} \mathrm{S}, 120^{\circ}-150^{\circ} \mathrm{E}$.

\begin{tabular}{|c|c|c|c|c|}
\hline & Model name & $\begin{array}{l}\text { Change in monsoon } \\
\text { precipitation }(\%)\end{array}$ & $\begin{array}{l}\text { Normalized change in monsoon } \\
\text { precipitation }\left(\% \mathrm{~K}^{-1}\right)\end{array}$ & Classification \\
\hline 1 & ACCESS1.0 & 5.8 & 1.5 & MID \\
\hline 2 & ACCESS1.3 & -20.7 & -5.3 & DRY \\
\hline 3 & BCC_CSM1.1 & -3.9 & -1.1 & DRY \\
\hline 4 & BNU-ESM & 37.2 & 8.6 & WET \\
\hline 5 & CanESM2 & 6.4 & 1.4 & MID \\
\hline 6 & CCSM4 & 10.7 & 2.9 & MID \\
\hline 7 & CESM1(BGC) & 15.7 & 4.5 & WET \\
\hline 8 & CESM1(CAM5) & 11.8 & 2.9 & WET \\
\hline 9 & CMCC-CESM & -16.7 & -4.5 & DRY \\
\hline 10 & CMCC-CMS & -0.1 & 0.0 & MID \\
\hline 11 & CNRM-CM5 & 11.0 & 3.2 & WET \\
\hline 12 & CSIRO Mk3.6.0 & -42.9 & -11.1 & DRY \\
\hline 13 & FGOALS-g2 & 16.0 & 5.3 & WET \\
\hline 14 & FGOALS-s2 & 3.0 & 0.6 & MID \\
\hline 15 & FIO-ESM & 13.5 & 4.1 & WET \\
\hline 16 & GFDL CM3 & -3.5 & -0.7 & DRY \\
\hline 17 & GFDL-ESM2G & 8.7 & 3.1 & WET \\
\hline 18 & GFDL-ESM2M & 2.5 & 0.9 & MID \\
\hline 19 & GISS-E2-H & -26.1 & -8.9 & DRY \\
\hline 20 & GISS-E2-R & 8.4 & 3.3 & WET \\
\hline 21 & HadGEM2-AO & 0.3 & 0.1 & MID \\
\hline 22 & HadGEM2-CC & 17.1 & 3.8 & WET \\
\hline 23 & HadGEM2-ES & 0.7 & 0.2 & MID \\
\hline 24 & IPSL-CM5A-LR & -4.4 & -1.0 & DRY \\
\hline 25 & IPSL-CM5A-MR & -10.9 & -2.5 & DRY \\
\hline 26 & MIROC5 & -1.9 & -0.6 & MID \\
\hline 27 & MIROC-ESM & -17.9 & -4.0 & DRY \\
\hline 28 & MIROC-ESM-CHEM & -20.3 & -4.3 & DRY \\
\hline 29 & MPI-ESM-LR & 4.6 & 1.3 & MID \\
\hline 30 & MPI-ESM-MR & -4.3 & -1.2 & DRY \\
\hline 31 & MRI-CGCM3 & 3.3 & 1.1 & MID \\
\hline 32 & NorESM1-M & 18.5 & 5.9 & WET \\
\hline \multirow[t]{2}{*}{33} & NorESM1-ME & 15.1 & 4.5 & WET \\
\hline & Average & 1.1 & 0.4 & \\
\hline
\end{tabular}

as changes in the temperature gradient between the $\mathrm{NH}$ and SH (e.g., Wang et al. 2012; Lee and Wang 2014; Wang et al. 2014). We investigate each of these drivers in turn and evaluate whether they play an important role in Australian monsoon precipitation changes in the CMIP5 ensemble.

\section{1) ROLE OF SST}

To identify relationships between temperature and monsoon precipitation anomalies in future climate simulations, changes in DJF Australian monsoon precipitation $\left(\% \mathrm{~K}^{-1}\right)$ across the 33 CMIP5 models were correlated with changes in DJF surface temperature $(\mathrm{K})$ for the same 33 models at each grid point. The resulting spatial pattern is shown in Fig. 4a. The local temperature change over northern Australia is negatively correlated with monsoon precipitation change, implying cooling or reduced warming is associated with increased precipitation. This anticorrelation is seen at interannual (Power et al. 1998) and climate change time scales (Wardle and Smith 2004) and is associated with increased precipitation and cloudiness reducing surface temperatures (Power et al. 1998). Another region of strong negative correlation is in the western and central tropical Pacific, implying that models with greater warming in this region have reduced Australian summer monsoon precipitation in future climate. We again note that this is a region where models have large biases in present day SST, and also large disagreement about the amount of future SST warming (e.g., Grose et al. 2014a,b).

Following Watterson (2012), we also calculate a Pacific-Indian dipole (PID) index to measure the relative amount of warming in the tropical Pacific and Indian Oceans. This index was found by Watterson (2012) to 


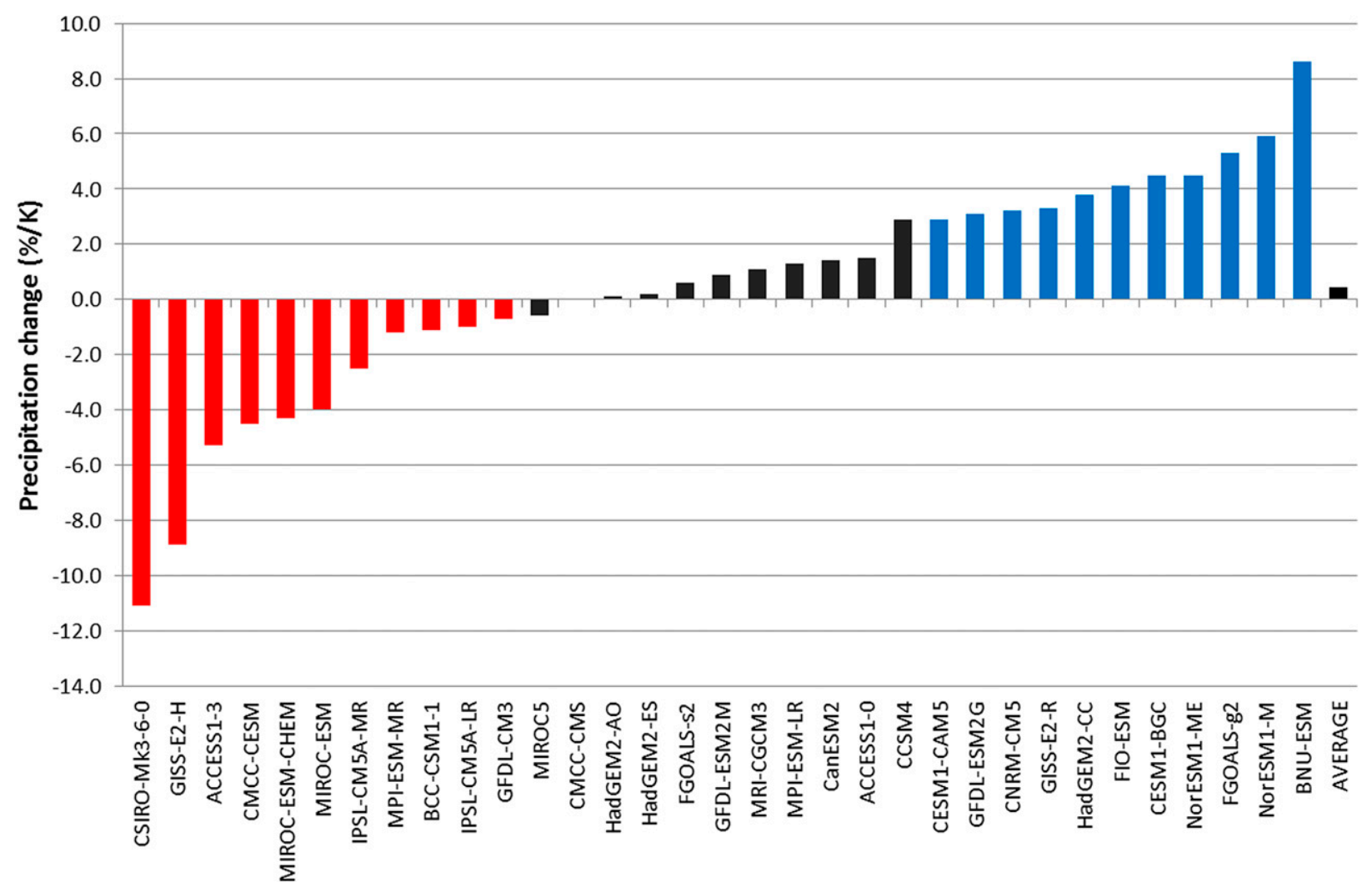

FIG. 3. Change in DJF Australian summer monsoon precipitation (\% $\left.\mathrm{K}^{-1}\right)$ for RCP8.5 (2070-99) minus Historical (1970-99). Monsoon precipitation is calculated for land points in the domain $10^{\circ}-20^{\circ} \mathrm{S}, 120^{\circ}-150^{\circ} \mathrm{E}$. Red bars indicate DRY models, and blue bars indicate WET models (see text for details).

correlate strongly with changes in average Australian precipitation. The PID index is the average SST in the Pacific Ocean box $10^{\circ} \mathrm{N}-10^{\circ} \mathrm{S}, 150^{\circ}-200^{\circ} \mathrm{E}$ minus the average SST in the Indian Ocean box $5^{\circ} \mathrm{N}-15^{\circ} \mathrm{S}, 70^{\circ}-120^{\circ} \mathrm{E}$ (shown in Fig. 4b). Here, we compare changes in the DJF PID with changes in DJF precipitation to identify precipitation regions with a strong connection to Pacific and Indian Ocean SST changes. The correlation between PID changes and precipitation changes at each model grid point over the ensemble of CMIP5 models is shown in Fig. 4b. There are moderate to strong negative correlations over most of Australia, including the monsoon region, indicating that models with greater warming in the Pacific than Indian Ocean tend to have smaller or negative changes in precipitation. However, this correlation is predominantly due to the relationship of Australian precipitation with SSTs in the Pacific Ocean box (Fig. 4c) rather than the Indian Ocean box (Fig. 4d). This suggests that the amount of warming in the western tropical Pacific is an important factor in the change in Australian summer monsoon precipitation, while the relative warming of Pacific versus Indian Oceans plays a smaller role. The influence of warming in the equatorial
Pacific on northern Australian precipitation in future climate simulations was also identified by Watterson (2012) and Grose et al. (2014b).

\section{2) Role OF LAND-OCEAN TEMPERATURE CONTRAST}

As the land-ocean thermal contrast plays an important role in driving regional monsoon circulations (e.g., Christensen et al. 2013), enhanced heating of land or ocean areas in the future may lead to a strengthening or weakening of monsoon circulations (e.g., Wardle and Smith 2004; Wang et al. 2014). To investigate the extent to which this mechanism is important for the Australian monsoon, we calculate the change in the land-ocean temperature contrast for both DJF and SeptemberNovember (SON) seasons and compare this with the change in Australian summer monsoon precipitation (defined as above), shown in Fig. 5. The land-ocean temperature contrast is calculated over $10^{\circ}-20^{\circ} \mathrm{S}, 120^{\circ}-$ $150^{\circ} \mathrm{E}$ for land temperature and $10^{\circ}-20^{\circ} \mathrm{S}, 100^{\circ}-160^{\circ} \mathrm{E}$ for ocean temperature.

There are significant negative correlations between both DJF (Fig. 5a) and SON (Fig. 5b) land-ocean 
(a)

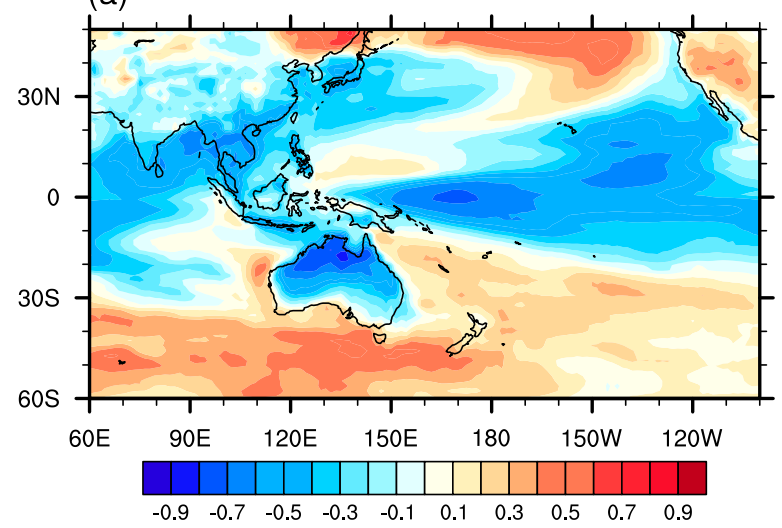

(c)

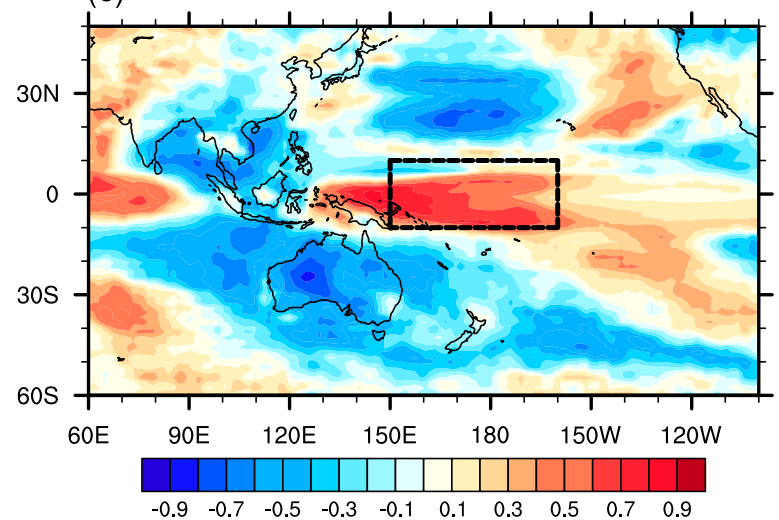

(b)

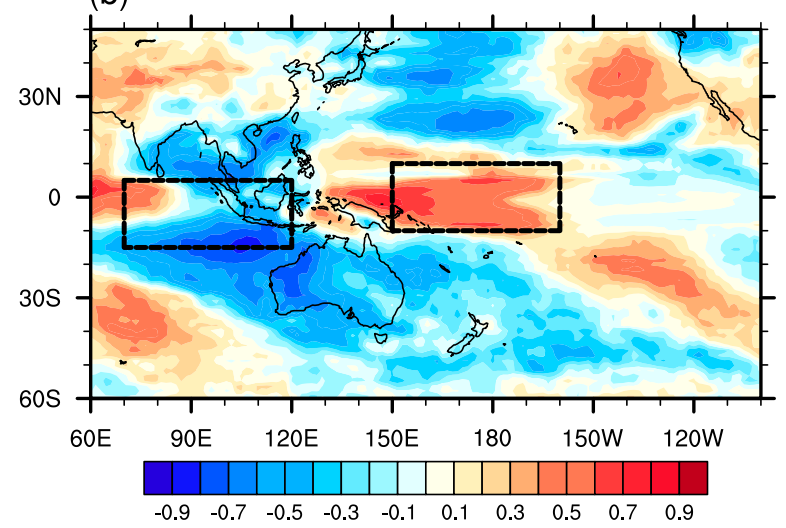

(d)

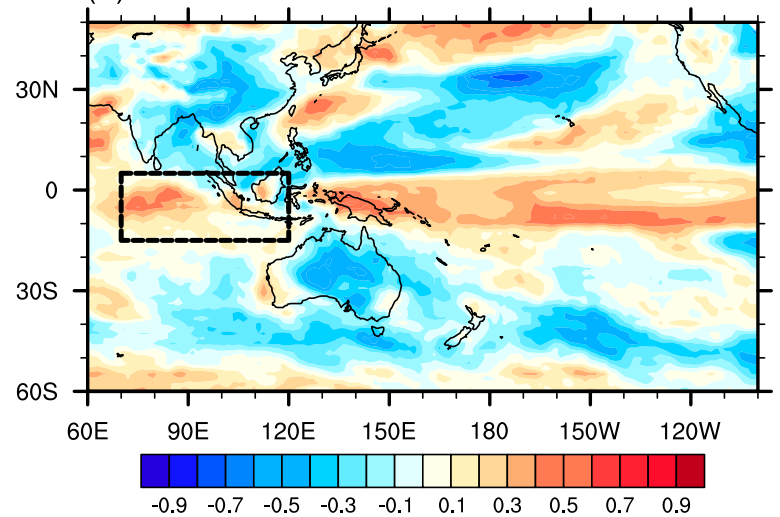

FIG. 4. (a) Correlation across models of change in DJF Australian monsoon precipitation (\% $\mathrm{K}^{-1}$ ) with change in DJF surface temperature $\left(\mathrm{K} \mathrm{K}^{-1}\right)$. (b) Correlation across models of change in DJF PID index (see text for definition) with change in DJF precipitation $\left(\% \mathrm{~K}^{-1}\right)$. (c) As in (b), but using Pacific Ocean box surface temperature change. (d) As in (b), but using Indian Ocean box surface temperature change. Changes are anomalies for RCP8.5 (2070-99) minus Historical (1970-99). Locations of Pacific and Indian Ocean boxes are shown. Note that correlation coefficients with magnitude $>0.34$ are significant at the $5 \%$ level.

temperature contrast changes and DJF precipitation changes, implying that models with greater seasonal warming over land (increased land-ocean temperature contrast) have reduced precipitation. This result suggests that precipitation changes are driving local temperatures, rather than temperature driving precipitation changes, consistent with the spatial correlations shown in Fig. 4a. This is in contrast with the basin-scale relationship discussed by Wang et al. (2014), whereby stronger warming over Asia than the adjacent Pacific Ocean leads to a pressure gradient that favors onshore moisture transport. We also note that different calculations of the land-ocean thermal contrast have been used in monsoon studies, and several studies showed the offsetting effects of the thermal contrast in the surface and low troposphere and the upper troposphere in influencing the monsoon development and intensity (e.g., Sun et al. 2010; Dai et al. 2013). Such detailed analyses will be pursued in future studies.

\section{3) ROLE OF INTERHEMISPHERIC TEMPERATURE GRADIENT}

Previous studies have suggested that greater warming in the $\mathrm{NH}$ than the $\mathrm{SH}$ will drive an enhanced crossequatorial flow from $\mathrm{SH}$ to $\mathrm{NH}$, enhancing the Asian summer monsoon and reducing the Australian summer monsoon (Wang et al. 2012; Lee and Wang 2014; Wang et al. 2014). However, the contribution of this process to Australian monsoon precipitation changes has not been quantified. Here, we investigate the influence of changes in the interhemispheric temperature gradient on the Australian summer monsoon in the CMIP5 ensemble. The interhemispheric temperature gradient is calculated over all latitudes and over the near-tropical domain $\left(0^{\circ}-40^{\circ} \mathrm{N}\right.$ versus $\left.0^{\circ}-40^{\circ} \mathrm{S}\right)$.

The change in annual mean interhemispheric temperature gradient versus Australian summer monsoon precipitation change is shown in Fig. 6. Changes in 

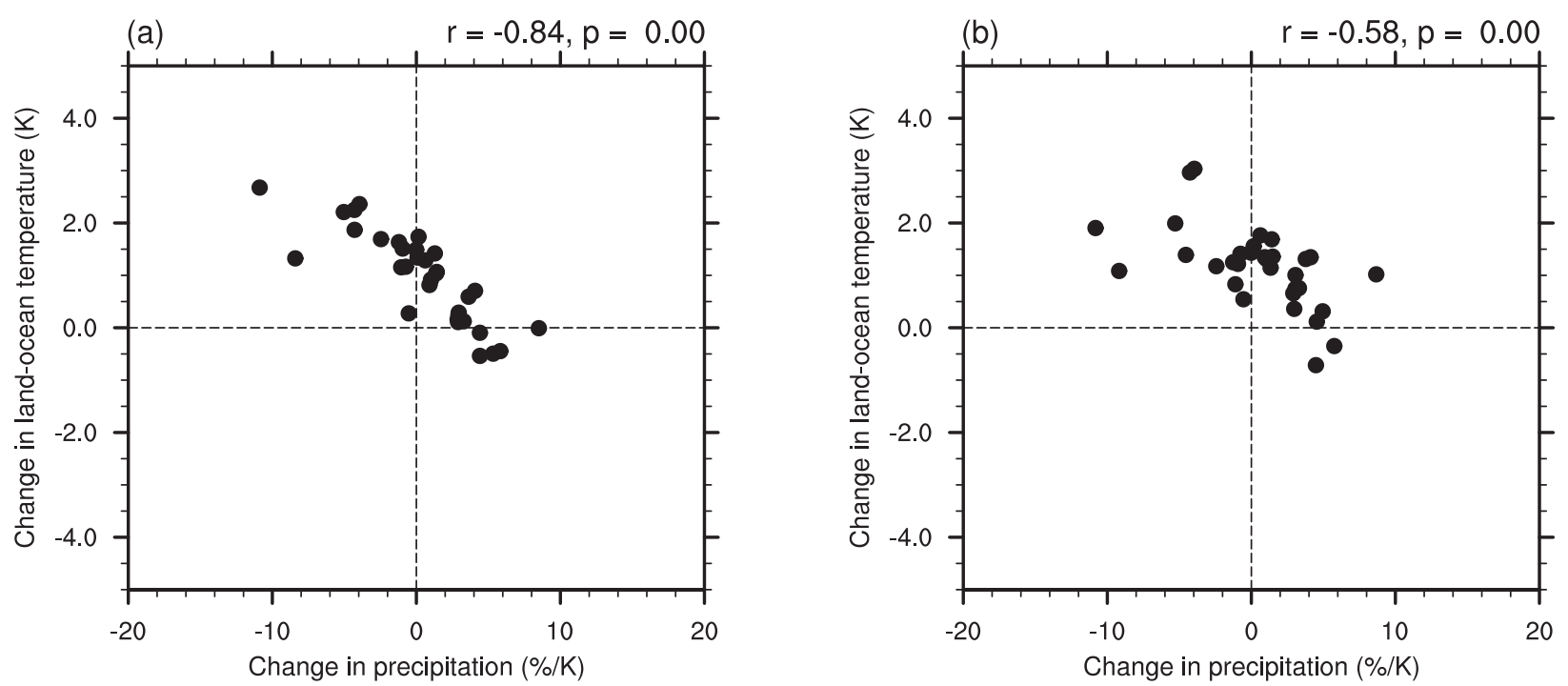

FIG. 5. Change in DJF monsoon precipitation ( $\% \mathrm{~K}^{-1}$ ) vs change in (a) DJF and (b) SON land-ocean temperature contrast (K). Changes are anomalies for RCP8.5 (2070-99) minus Historical (1970-99). Domains used for calculations are $10^{\circ}-20^{\circ} \mathrm{S}, 120^{\circ}-150^{\circ} \mathrm{E}$ for precipitation and land temperature, $10^{\circ}-20^{\circ} \mathrm{S}, 100^{\circ}-160^{\circ} \mathrm{E}$ for ocean temperature. Correlation coefficients and $p$ values are shown at top right.

interhemispheric temperature gradient are generally positive, indicating that $\mathrm{NH}$ warms more than $\mathrm{SH}$. The change in temperature gradient over all latitudes $\left(0^{\circ}-\right.$ $90^{\circ} \mathrm{N}$ versus $\left.0^{\circ}-90^{\circ} \mathrm{S}\right)$ is not significantly correlated with change in Australian summer monsoon precipitation (Fig. 6a). There is a weak negative correlation $(r=-0.33)$ between changes in near-tropical temperature gradient $\left(0^{\circ}-40^{\circ} \mathrm{N}\right.$ versus $\left.0^{\circ}-40^{\circ} \mathrm{S}\right)$ and monsoon precipitation (Fig. 6b), that is, significant at the $6 \%$ level. This implies that a stronger interhemispheric temperature gradient (i.e., more $\mathrm{NH}$ warming than $\mathrm{SH}$ warming) over the near-tropical domain is associated with reduced Australian summer monsoon precipitation, as expected from dynamical considerations and as suggested in previous studies (Lee and Wang 2014; Wang et al. 2014). However, the weak correlation and the wide spread of model precipitation projections implies that interhemispheric temperature gradients and the resulting cross-equatorial circulation changes are not the primary driver of Australian summer monsoon changes in a warmer climate.
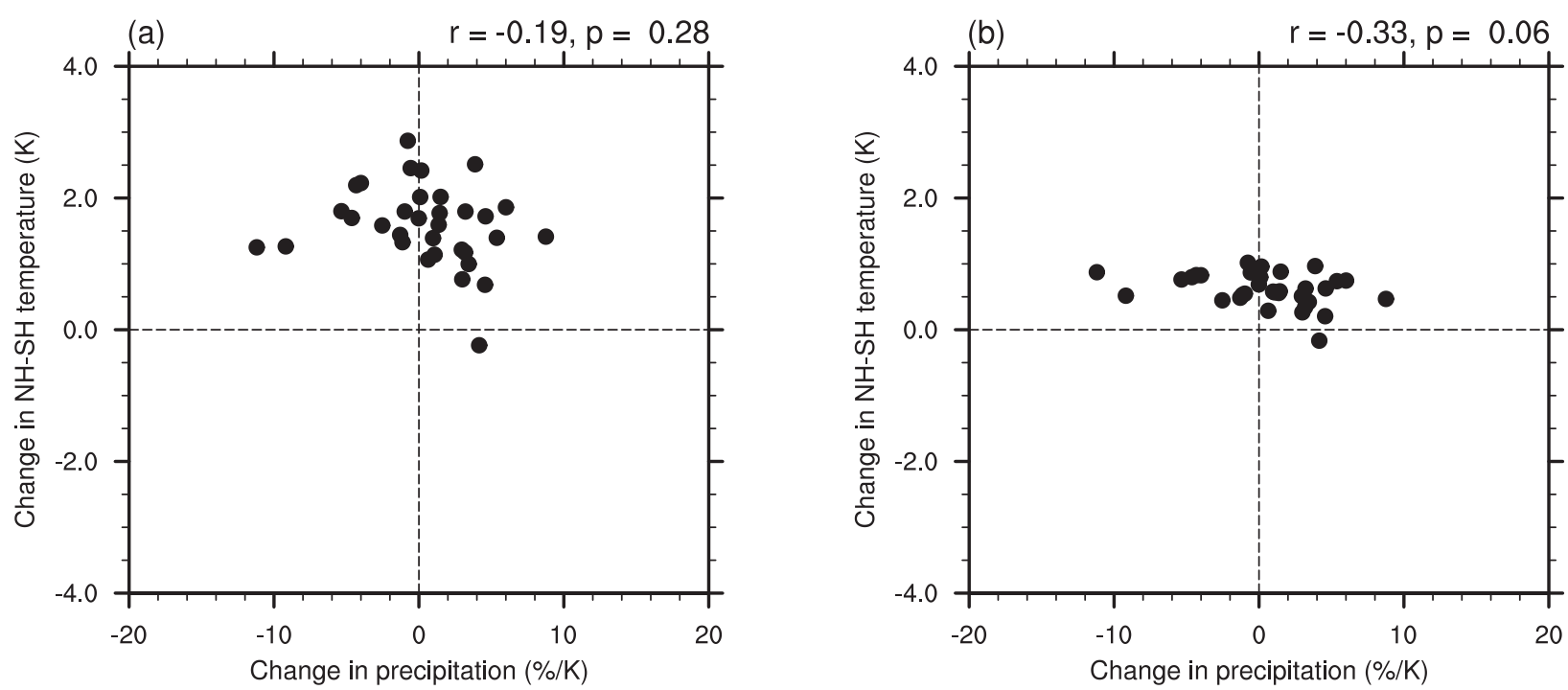

FIG. 6. Change in Australian summer (DJF) monsoon precipitation $\left(10^{\circ}-20^{\circ} \mathrm{S}, 120^{\circ}-150^{\circ} \mathrm{E}\right.$; \% $\left.\mathrm{K}^{-1}\right)$ vs change in annual average interhemispheric temperature gradient (K), that is, NH-SH (RCP8.5) minus NH-SH (Historical) for (a) all latitudes and (b) $0^{\circ}-40^{\circ} \mathrm{N}$ vs $0^{\circ}-40^{\circ} \mathrm{S}$. Changes are anomalies for RCP8.5 (2070-99) minus Historical (1970-99). Correlation coefficients and $p$ values are shown at top right. 
(a) $\Delta$ DJF precipitation (ALL) $\quad \mathrm{mm} /$ day $/ \mathrm{K}$

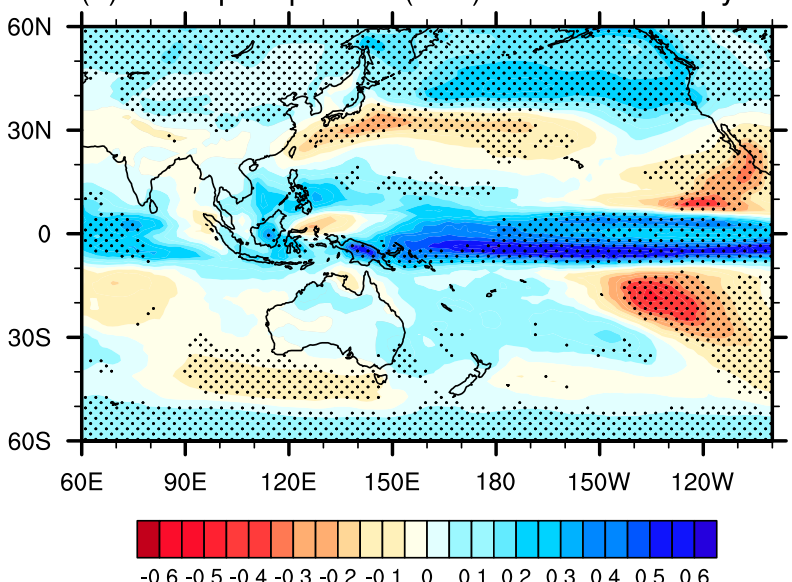

(c) $\Delta$ DJF precipitation (WET) $\quad \mathrm{mm} /$ day $/ \mathrm{K}$

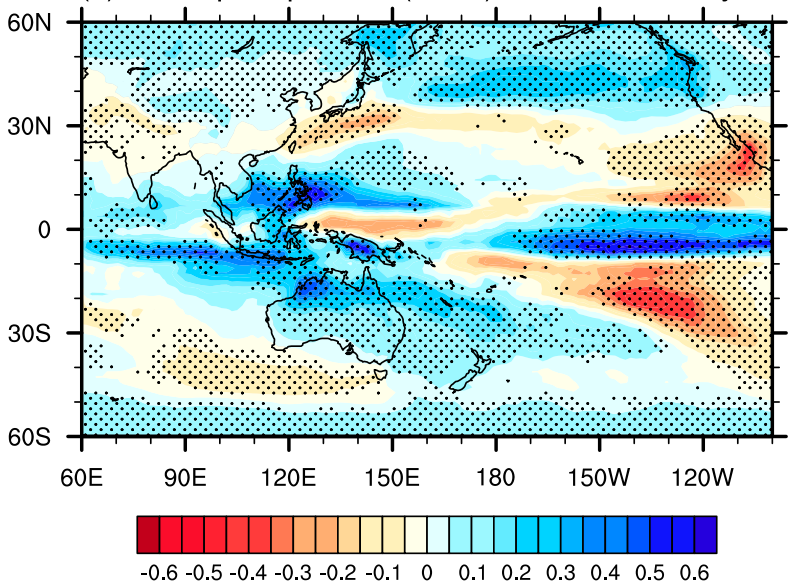

(b) $\Delta$ DJF precipitation (DRY) $\quad \mathrm{mm} /$ day $/ \mathrm{K}$

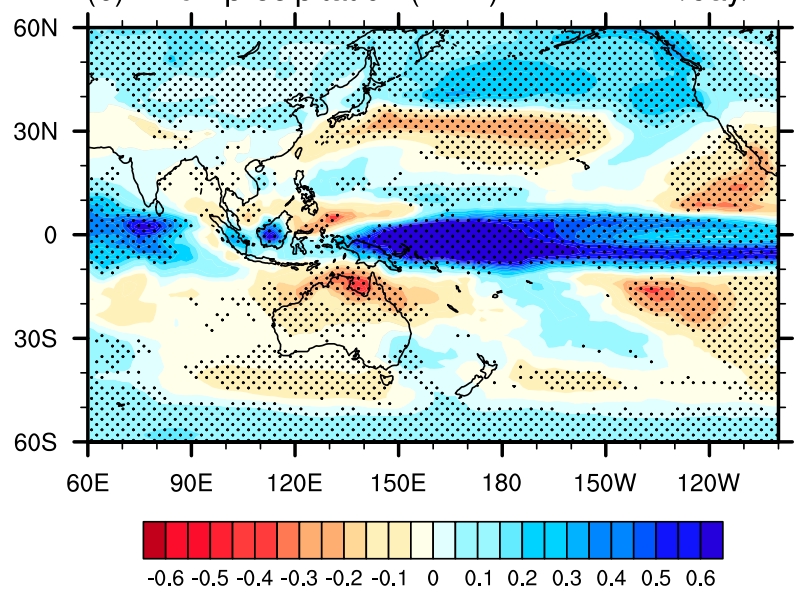

(d) $\triangle$ DJF precipitation (DRY - WET) $\mathrm{mm} /$ day $/ \mathrm{K}$

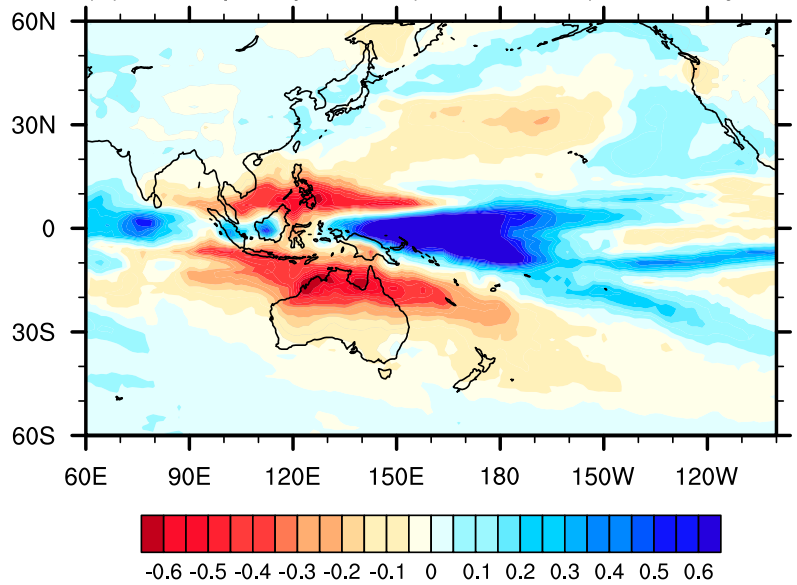

FIG. 7. DJF precipitation change (mm day ${ }^{-1} \mathrm{~K}^{-1}$ ) for RCP8.5 (2070-99) minus Historical (1970-99) for (a) all CMIP5 models, (b) subsets of the 11 models with largest negative anomaly (DRY), (c) the 11 models with largest positive anomaly (WET), and (d) difference between WET and DRY anomalies. See text and Table 2 for details of model classification. Stippling indicates regions where more than $80 \%$ of models agree on the sign of the change.

\section{Model projections by group}

To understand and potentially reduce the large model spread in monsoon precipitation projections, we consider whether models can be grouped based on some aspect of their current or projected climates. While Colman et al. (2011) and Moise et al. (2012) stratified CMIP3 models into "high," "medium," and "low" based on current climate summer monsoon precipitation, we find that this classification does not relate strongly to projected precipitation changes in CMIP5 models (not shown). Therefore, we instead group models based on their normalized Australian summer monsoon precipitation change $\left(\% \mathrm{~K}^{-1}\right)$, as shown in Fig. 3 and listed in Table 2. The highest tercile (11/33 models) of projected precipitation change is classified as WET, the lowest tercile of precipitation change is DRY, and the middle tercile is MID. The model classifications are listed in Table 2. Below, we examine the changes in precipitation, winds, and surface temperature for each group, as well as considering the role of model biases in influencing projected precipitation changes.

\section{a. Changes in precipitation}

The change in DJF precipitation (RCP8.5 2070-99 minus Historical 1970-99) for all models and for the DRY and WET groups is shown in Fig. 7. There is a region of drying centered over northern Australia in the DRY model mean (MM) by definition, although the largest negative anomalies occur over the adjacent Gulf of Carpentaria. The DRY MM (Fig. 7b) displays particularly large increases in precipitation over the western equatorial Pacific from New Guinea to east of the date 
(a) $\triangle$ DJF surface temperature (ALL)

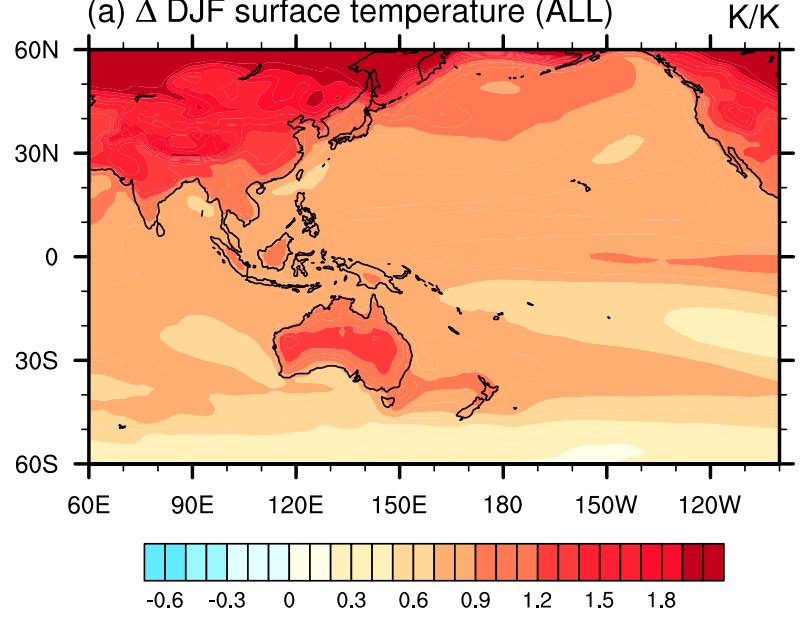

(c) $\Delta$ DJF surface temperature (WET) $\quad \mathrm{K} / \mathrm{K}$

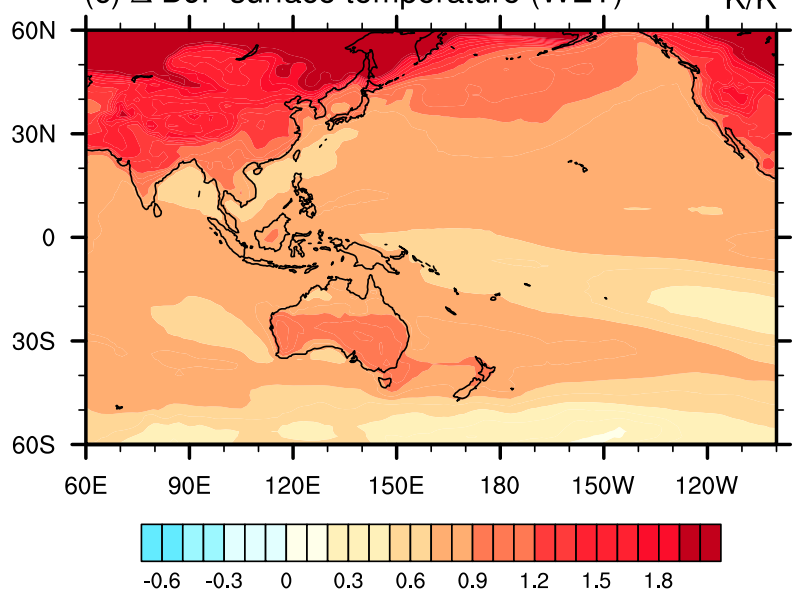

(b) $\Delta$ DJF surface temperature (DRY)

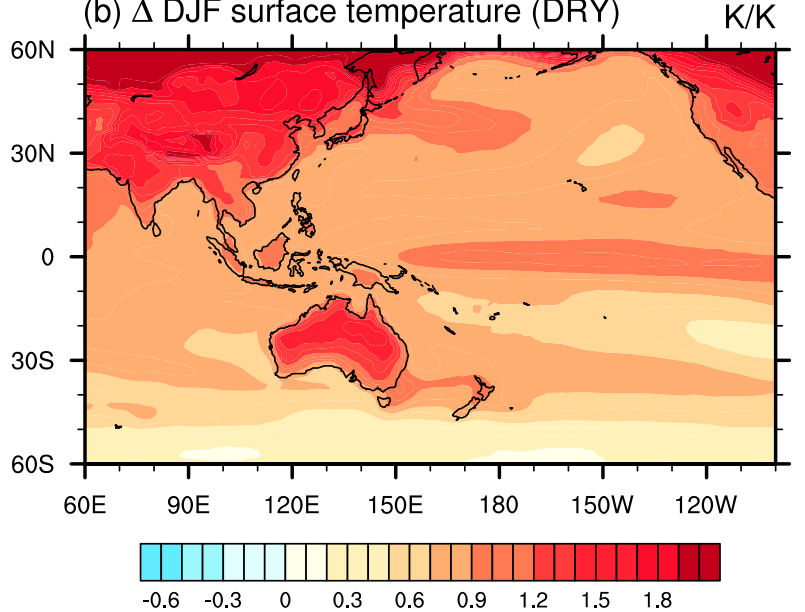

(d) $\Delta$ DJF surface temperature (DRY-WET) K/K

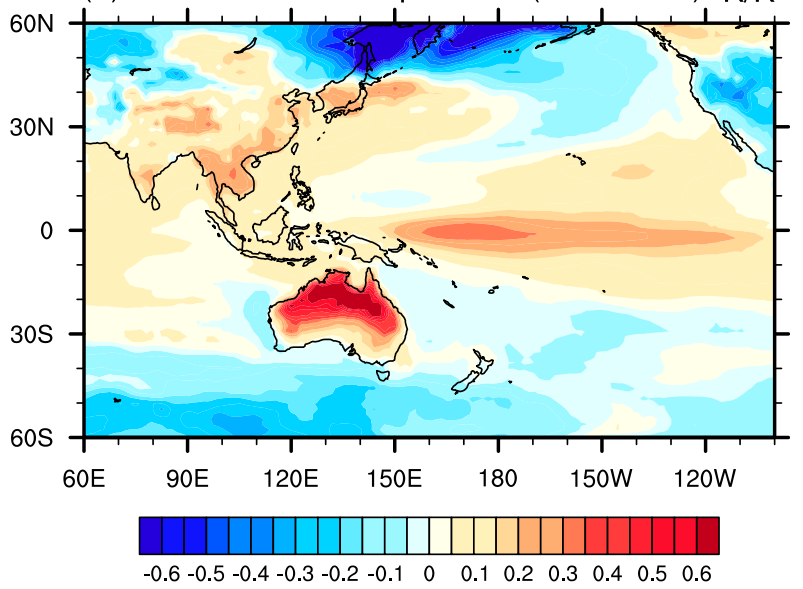

FIG. 8. DJF surface temperature change $\left(\mathrm{K} \mathrm{K}^{-1}\right)$ for RCP8.5 (2070-99) minus Historical (1970-99) for (a) all CMIP5 models, (b) DRY models, (c) WET models, and (d) difference between DRY and WET anomalies. Temperature change is normalized by global change. See text and Table 2 for details of model classification.

line. The WET MM (Fig. 7c) shows increased precipitation over all of Australia as well as the southwest Pacific (the region of the SPCZ), with high model agreement. The largest precipitation increase in the WET MM is in the eastern equatorial Pacific, with drying in the southeast Pacific extending toward the equator near the date line.

The difference between DRY and WET anomalies (Fig. 7d) consists of a large positive anomaly in the western equatorial Pacific and a large negative anomaly over northern Australia and also to the north of the equator in the western Pacific. We note that the DRY minus WET (Fig. 7d) precipitation anomalies are of similar magnitude to the projected changes (Figs. 7a-c). These results suggest that the changes in DJF precipitation over northern Australia are associated with coherent large-scale changes in tropical precipitation, including the location of maximum equatorial precipitation increases in the western, central, or eastern equatorial Pacific as well as accompanying changes in the intensity and location of the SPCZ and intertropical convergence zone (ITCZ).

\section{b. Changes in temperature and winds}

We now consider the corresponding temperature and 850-hPa wind changes for each of the model groups. The change in DJF surface temperature (RCP8.5 2070-99 minus Historical 1970-99) is shown in Fig. 8. There are several clear differences between DRY and WET MM changes in the tropical Pacific. The enhanced equatorial warming (Liu et al. 2005; Xie et al. 2010) is greatest in the DRY MM (Fig. 8b) and barely evident in the WET MM (Fig. 8c). The difference between DRY and WET surface temperature change (Fig. 8d) clearly shows 
(a) $\triangle \mathrm{DJF} 850 \mathrm{hPa}$ wind (ALL)

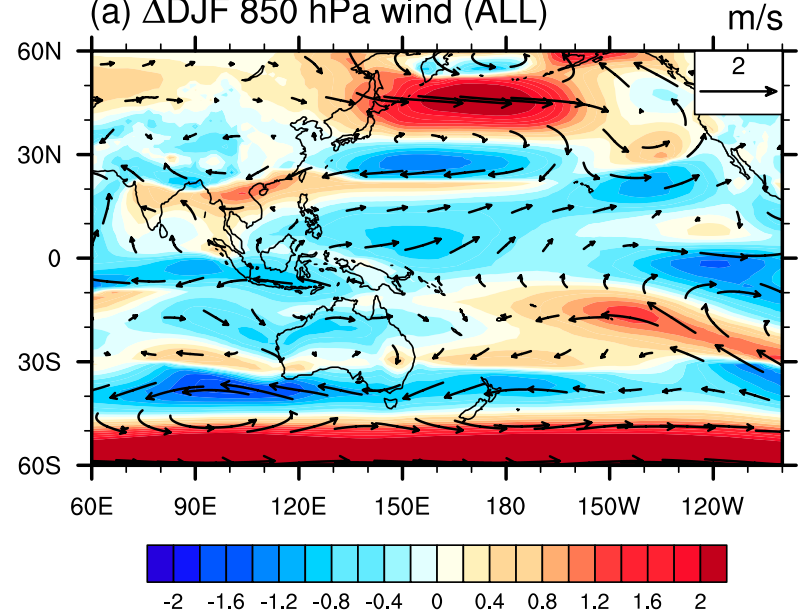

(c) $\triangle \mathrm{DJF} 850 \mathrm{hPa}$ wind (WET)

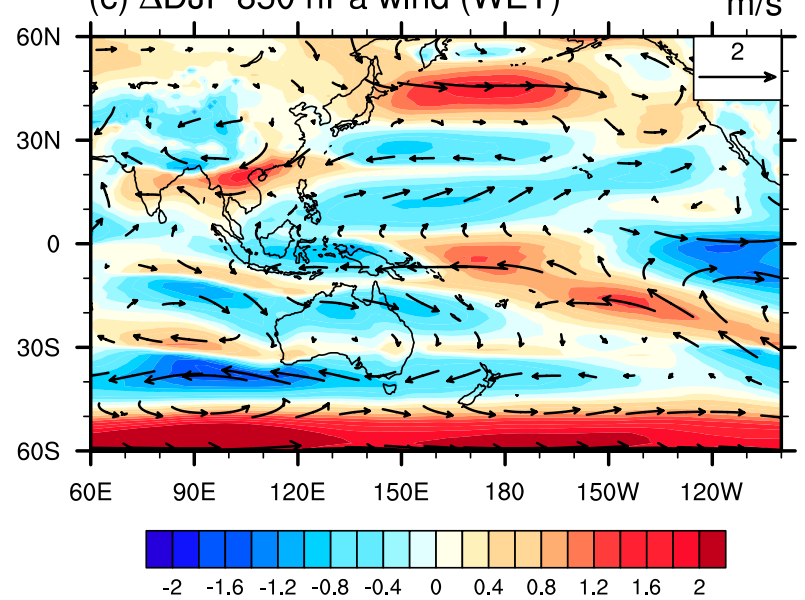

(b) $\triangle \mathrm{DJF} 850 \mathrm{hPa}$ wind (DRY)

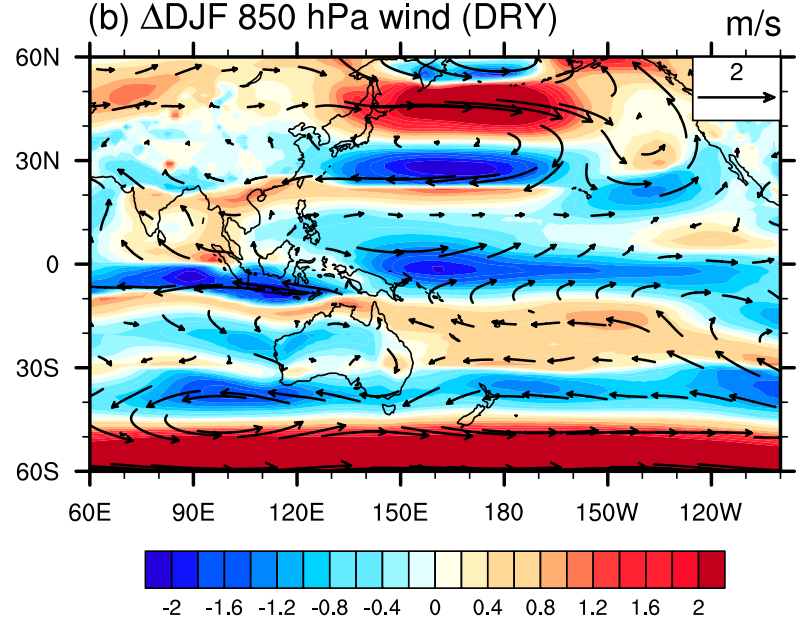

(d) $\triangle \mathrm{DJF} 850 \mathrm{hPa}$ wind (DRY - WET)

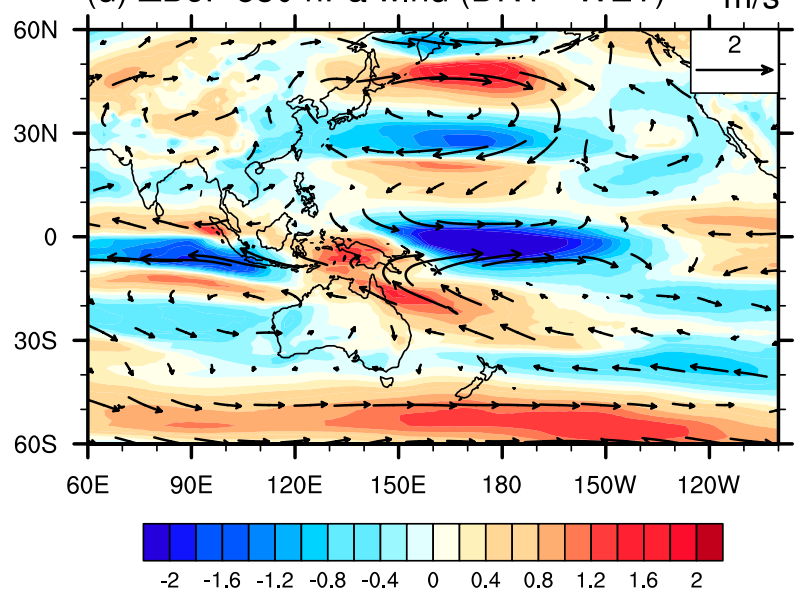

FIG. 9. DJF 850-hPa wind change for RCP8.5 (2070-99) minus Historical (1970-99) for (a) all CMIP5 models, (b) DRY models, (c) WET models, and (d) difference between DRY and WET anomalies. Wind vectors indicate change in wind direction, and colors indicate change in wind strength. See text and Table 2 for details of model classification.

much greater warming in the western equatorial Pacific and over northern Australia in the DRY MM than the WET MM. There is also a change in the sign of anomalies in Fig. 8d in the extratropics compared with the tropics. That is, warming is greater in the tropics in the DRY models than the WET models, and the opposite in the extratropics (a similar pattern is seen in Fig. 4a).

The tropical Pacific SST changes are consistent with the precipitation changes for each group, with largest precipitation increases occurring over regions of greater warming. This is consistent with previous studies that have highlighted the role of SST gradient or pattern changes in driving changes in tropical precipitation (Xie et al. 2010; Ma and Xie 2013; Huang et al. 2013). In the DRY models, enhanced warming in the equatorial Pacific anchors large increases in precipitation in this region, with reduced precipitation over northern Australia.
In the WET models, enhanced equatorial warming is largely confined to the eastern and central Pacific, where increased precipitation occurs. In contrast to the DRY models, there is little enhanced warming or precipitation in the western equatorial Pacific. The greater warming over Australian land areas for the DRY models than the WET models is consistent with the finding (see section 3) that changes in the land-ocean temperature gradient are inversely correlated with monsoon precipitation change, with precipitation apparently driving the temperature response.

Changes in 850-hPa winds are given in Fig. 9. The largest difference between DRY and WET model groups in the equatorial Pacific is that the DRY models (Fig. 9b) have greater weakening of winds in the western equatorial Pacific, where precipitation increases are largest, which is not evident in the WET models 

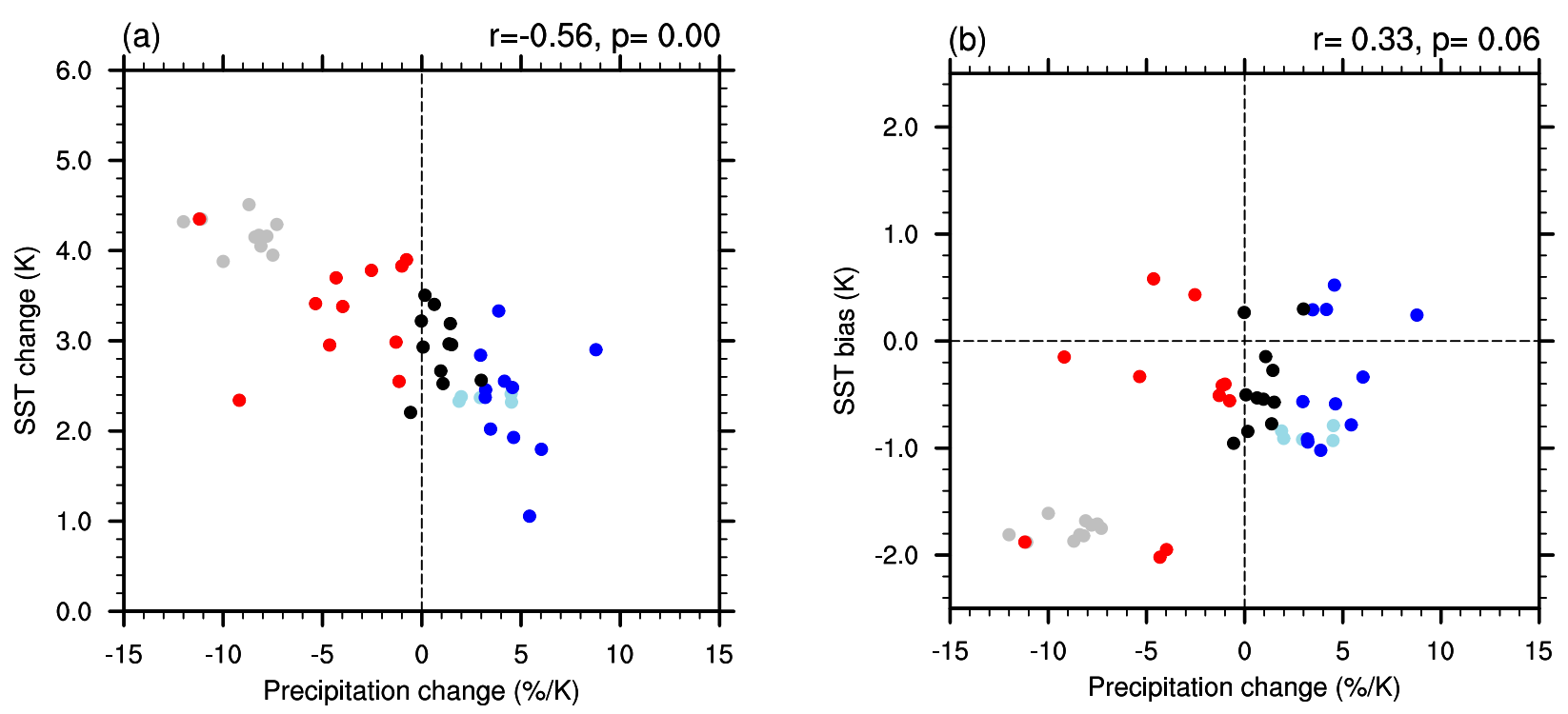

FIG. 10. Change in DJF Australian monsoon precipitation $\left(\% \mathrm{~K}^{-1}\right)$ vs (a) change in DJF WEP SST (K) averaged over the domain $10^{\circ} \mathrm{S}-$ $10^{\circ} \mathrm{N}, 150^{\circ}-200^{\circ} \mathrm{E}$ for RCP8.5 (2070-99) minus Historical (1970-99) and (b) model DJF SST bias in the same domain compared with HadISST SST data (1970-99) for all CMIP5 models. DRY, MID, and WET models are red, black, and blue circles, respectively. Gray circles are additional runs from CSIRO Mk3.6.0 model, and light blue circles are additional runs from CNRM-CM5 model.

(Fig. 9c). In the WET models, winds instead weaken in the eastern equatorial Pacific. Over northern Australia, there is a weakening of $850-\mathrm{hPa}$ winds in the MMM (ALL models, Fig. 9a). In the DRY MM, strengthened trade winds and weakened monsoon westerlies imply a northward-shifted monsoon trough, whereas wind anomalies are smaller and northwesterly in direction over northern Australia in the WET MM. Thus, the wind changes imply that onshore moisture transport to northern Australia is reduced in the DRY models but enhanced in the WET models.

\section{c. Comparison with biases in precipitation and temperature}

The projected changes in temperature and precipitation for each model group (Figs. 7, 8) can be compared with the model biases (Supplementary Figs. 1 and 2), comparing Historical MM SST with HadISST observations and Historical MM precipitation with CMAP observations from the same periods. It is evident that the region of large SST anomalies in the western equatorial Pacific (WEP) is also a region of large model biases, particularly in the DRY models (see Fig. 8b and Supplementary Fig. 1b). The DRY models also have a very marked dry precipitation bias in the WEP region (Supplementary Fig. 2b) and simulate large precipitation increases (Fig. 7b) here. In contrast, the WET models have smaller SST (Supplementary Fig. 1d) and precipitation (Supplementary Fig. 2d) biases in the WEP region and simulate smaller SST warming (Fig. 8c) and little, if any, precipitation increases (Fig. 7c) in this region. Instead, the WET models are too wet over most of Australia, including the monsoon northwest in the historical period (Supplementary Fig. 2d), and simulate increased precipitation over all of Australia in future climate (Fig. 7c).

The relationships between Australian monsoon precipitation increases and model WEP SST warming and WEP SST biases are summarized in Fig. 10. The WEP SST bias is calculated over the domain $10^{\circ} \mathrm{S}-10^{\circ} \mathrm{N}, 150^{\circ}-$ $200^{\circ} \mathrm{E}$ using HadISST observations for 1970-99 (similar results are obtained using root-mean-square error instead of bias, not shown). All models are included, with DRY models shown as red circles and WET models as blue circles. For comparison, multiple realizations from two models (CSIRO Mk3.6.0 and CNRM-CM5) are also included, although only the first realization for each model is used to calculate statistics. Changes in DJF monsoon precipitation are significantly negatively correlated with changes in DJF WEP SST (Fig. 10a), in agreement with earlier analysis (Figs. 4a, 8). In addition, changes in DJF monsoon precipitation are positively correlated with DJF WEP SST bias (significant at the $6 \%$ level), shown in Fig. 10b. However, it is evident that the strength of this correlation is largely due to the three models with largest WEP SST biases: CSIRO Mk3.6.0, MIROC-ESM, and MIROC-ESM-CHEM. The additional realizations from two models show that intramodel spread, due to natural variability, is generally small compared with the spread of the multimodel 
(a) $\Delta P_{t}$

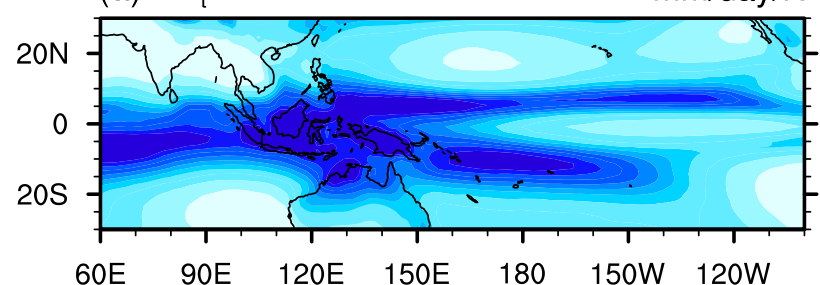

(c) $\Delta \mathrm{P}_{\text {weak }}$

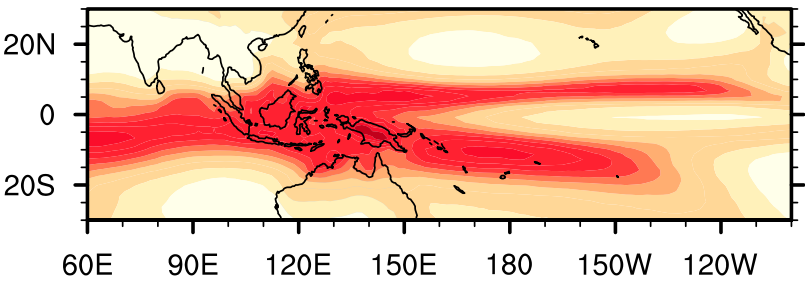

(e) $\Delta P_{\text {cross }}$

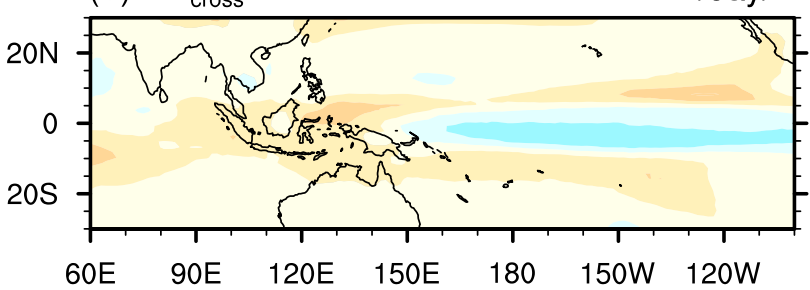

(b) $\Delta P_{r h}$

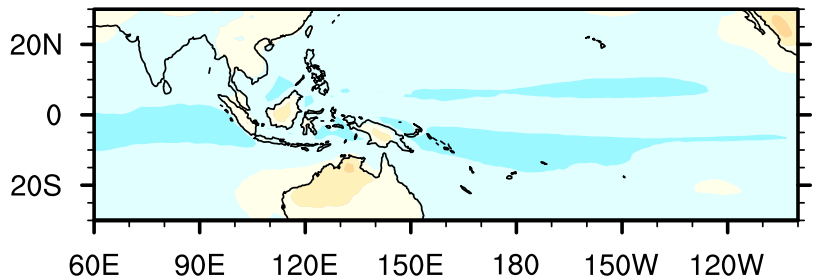

(d) $\Delta \mathrm{P}_{\text {shift }}$

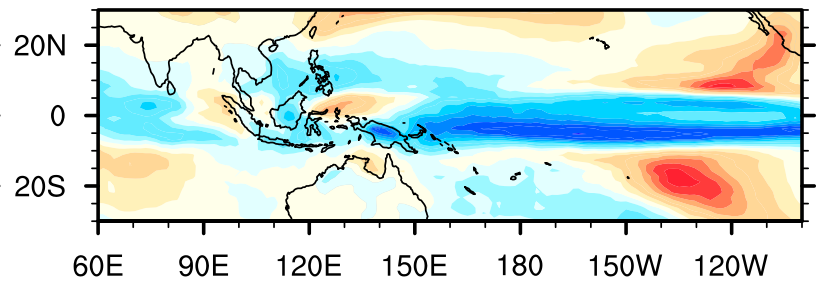

(f) $\Delta \mathrm{P}_{\mathrm{t}}+\Delta \mathrm{P}_{\text {weak }}$

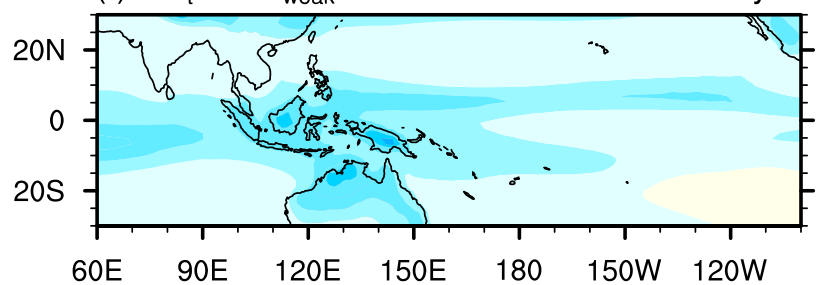

(g) $\Delta P_{\text {total }}$ $\mathrm{mm} /$ day $/ \mathrm{K}$

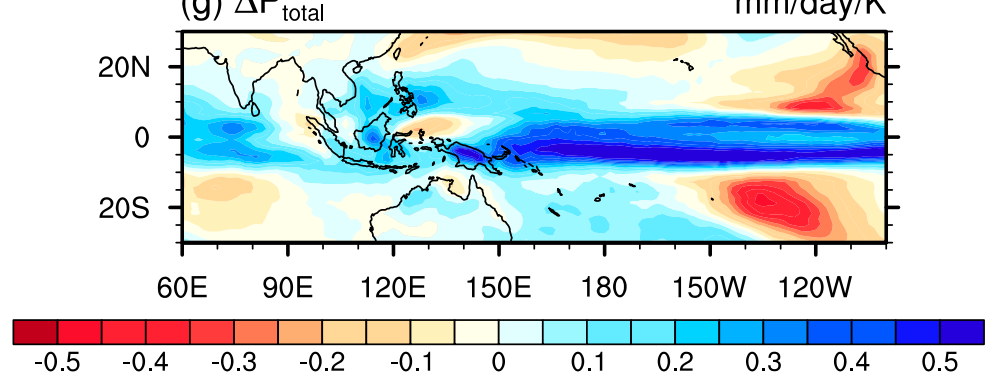

FIG. 11. CMIP5 MMM decomposition of DJF precipitation change ( $\mathrm{mm} \mathrm{day}^{-1} \mathrm{~K}^{-1}$ ) for RCP8.5 (2070-99) minus Historical (1970-99) following the approach of Chadwick et al. (2013). The components are described in the text.

ensemble. Correlations between WEP SST bias and WEP SST warming were not significant (not shown), in agreement with Grose et al.'s (2014b) analysis for a larger equatorial Pacific domain.

\section{Decomposition of precipitation changes}

\section{a. Multimodel mean and individual models}

Following the method of Chadwick et al. (2013) as outlined in section 2, the changes in DJF precipitation for each CMIP5 model are decomposed into five components: 1) thermal component due to Clausius-Clapeyron, 2) relative humidity change, 3) dynamic component due to weakening of the circulation, 4) dynamic component due to spatial shifts in convection, and 5) the nonlinear term. An additional plot is also included to show the sum of terms (1) and (3), as Chadwick et al. (2013) identified that these terms nearly cancel in the multimodel mean.

The DJF MMM precipitation decomposition for all 33 CMIP5 models is shown in Fig. 11. The thermodynamic term (Fig. 11a) is positive everywhere (consistent with increased temperatures) with the pattern following the Historical precipitation pattern, that is, a "wet gets wetter" response. The changes due to relative humidity (Fig. 11b) are small, with negative anomalies over land, particularly over northwest Australia. The dynamic term due to the weakening of the mean 
(a) $\Delta P_{\text {rh }}(D R Y)$

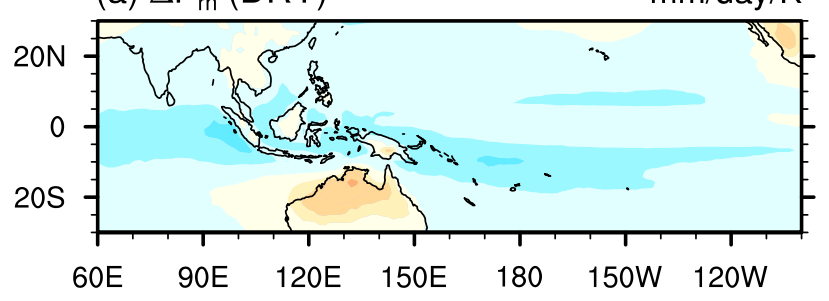

(c) $\Delta P_{\text {shift }}(\mathrm{DRY})$

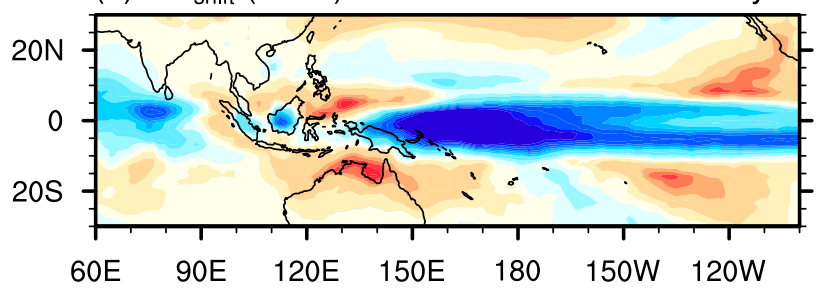

(e) $\Delta \mathrm{P}_{\mathrm{t}}+\Delta \mathrm{P}_{\text {weak }}(\mathrm{DRY})$

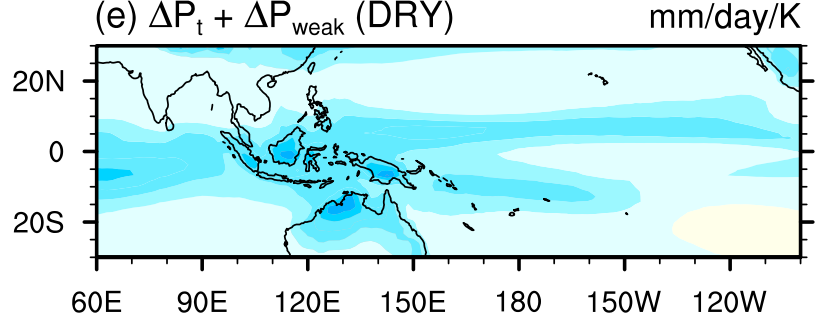

(g) $\Delta P_{\text {total }}(D R Y)$

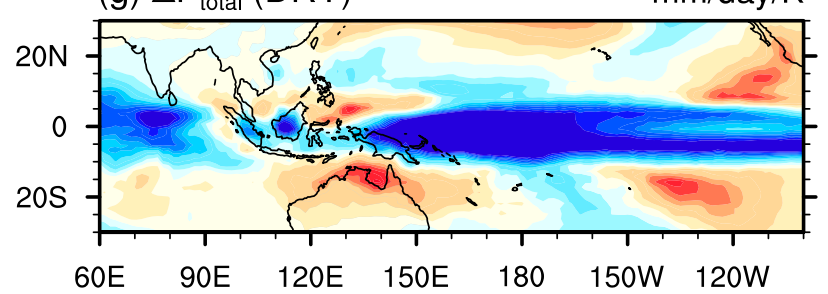

(b) $\Delta \mathrm{P}_{\mathrm{rh}}$ (WET) $\mathrm{mm} /$ day/K

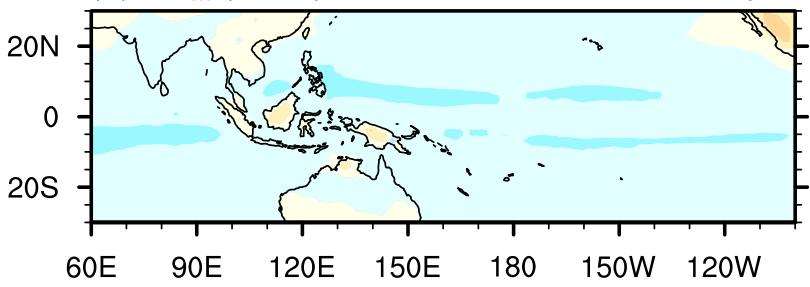

(d) $\Delta \mathrm{P}_{\text {shift }}(\mathrm{WET})$

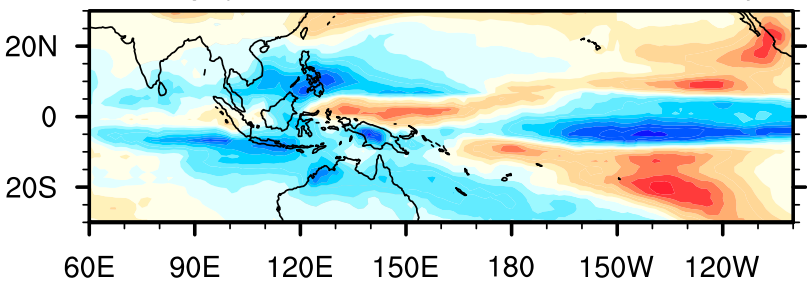

(f) $\Delta \mathrm{P}_{\mathrm{t}}+\Delta \mathrm{P}_{\text {weak }}(\mathrm{WET})$

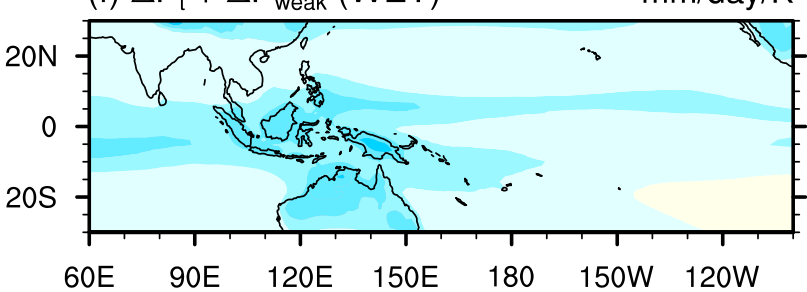

(h) $\Delta \mathrm{P}_{\text {total }}(\mathrm{WET})$

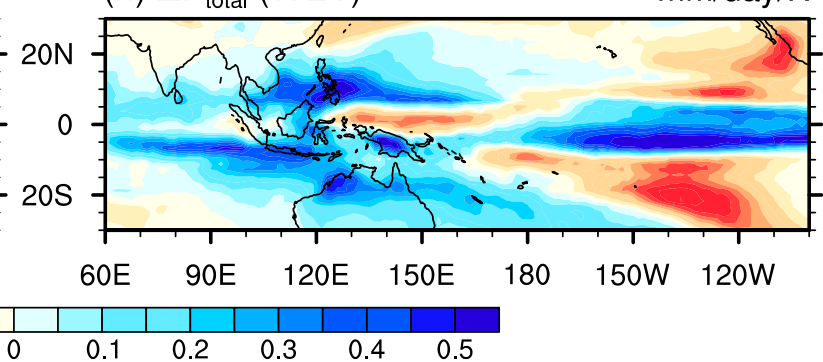

FIG. 12. Selected terms in decomposition of DJF precipitation change ( $\mathrm{mm} \mathrm{day}^{-1} \mathrm{~K}^{-1}$ ) for RCP8.5 (2070-99) minus Historical (197099) for (left) DRY and (right) WET models: (a),(b) relative humidity term; (c),(d) spatial shift in convection; (e),(f) sum of thermodynamic term and dynamical weakening term; and $(\mathrm{g}),(\mathrm{h})$ total precipitation change.

tropical circulation (Fig. 11c) is negative everywhere and follows the pattern of Historical convergence and precipitation. As can be seen in Fig. 11f, the thermodynamic and mean dynamic terms nearly cancel, with a positive residual that makes a major contribution to total precipitation change over northern Australia. Over the wider tropical Pacific region, the component due to spatial shifts in convergence (Fig. 11d) is very similar to the total precipitation change (Fig. 11g), consistent with Chadwick et al. (2013) and Kent et al. (2015). However, over the northern Australian monsoon domain, this term is smaller than the relative humidity, nonlinear, or residual terms.

\section{b. Decomposition for DRY and WET models}

The decomposition method is also applied to the groups of DRY and WET models to determine whether there is a consistent difference in the dominant terms of DJF precipitation change for the different groups. The spatial plots of the most important terms are shown for both DRY and WET models in Fig. 12. The average of all terms over the Australian monsoon domain for all, DRY, MID, and WET models is shown in Fig. 13.

The relative humidity term (Figs. 12a,b) includes a region of drying over northern Australia for the DRY models with little change in the WET models. The 
(a)

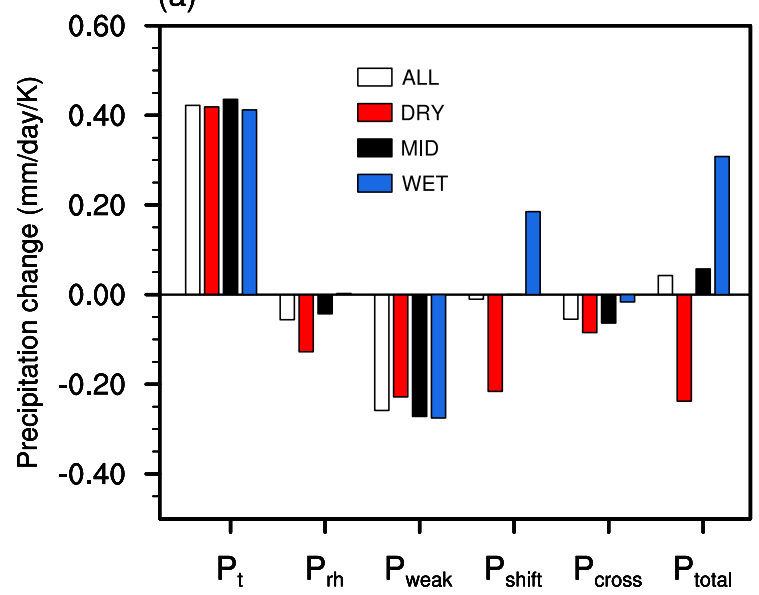

(b)

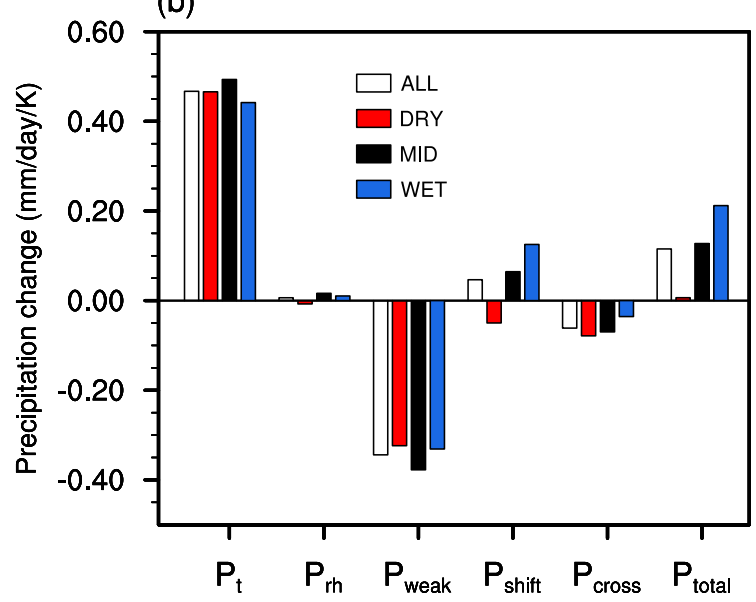

FIG. 13. The components of DJF Australian monsoon precipitation change ( $m$ day $^{-1} \mathrm{~K}^{-1}$ ) for RCP8.5 (2070-99) minus Historical (1970-99) for (a) $10^{\circ}-20^{\circ} \mathrm{S}, 120^{\circ}-150^{\circ} \mathrm{E}$ land points only and (b) $0^{\circ}-20^{\circ} \mathrm{S}, 120^{\circ}-150^{\circ} \mathrm{E}$ land and ocean points. White bars are all CMIP5 models, red bars are DRY models, black bars are MID models, and blue bars are WET models (see Table 2 for model classification).

largest difference between the DRY and WET models over northern Australia is due to the spatial shift term, with anomalies of opposite sign (Figs. 12c,d). While the residual (thermodynamic plus dynamic weakening) term (Figs. 12e,f) contributes a precipitation anomaly over northern Australia of similar magnitude to the spatial shift term, the sign of the residual anomaly is positive for both WET and DRY models and therefore cannot explain the difference in total precipitation change between the two groups of models. Interestingly, the residual term is actually wetter over this region for the DRY models than the WET models, largely due to a greater weakening of the circulation in the WET models (see Fig. 13). Over the wider tropical Pacific domain, the total precipitation changes for DRY and WET models (Figs. 12g,h) closely match the spatial shift term (Figs. 12c,d), as was the case for the CMIP5 MMM (Fig. 11).

The average DJF Australian monsoon precipitation change due to each of the terms in the decomposition for the WET and DRY models, and for all CMIP5 models, is shown in Fig. 13. The decomposition of monsoon precipitation change is shown over the standard land domain $10^{\circ}-20^{\circ} \mathrm{S}, 120^{\circ}-150^{\circ} \mathrm{E}$ as well as a larger land and ocean domain $0^{\circ}-20^{\circ} \mathrm{S}, 120^{\circ}-150^{\circ} \mathrm{E}$. For the land domain (Fig. 13a), the largest terms for all model groups are the positive thermodynamic components, followed by the negative dynamic weakening components. The sum of these two terms is positive in all cases (not shown). The difference between DRY and WET models is most strongly driven by the spatial shift component, but it is also due to the relative humidity and, to a lesser extent, the nonlinear terms. For the larger domain including land and ocean (Fig. 13b), the relative humidity term is not important, and the smaller difference between DRY and WET total precipitation change is almost entirely due to the spatial shift term.

\section{Discussion and conclusions}

This study has examined the results from 33 CMIP5 models to investigate the processes leading to changes in Australian summer monsoon precipitation in future climate projections. The aim was to explain the large spread of model monsoon precipitation projections and to identify mechanisms driving the simulated monsoon precipitation change. We also aimed to reduce uncertainty in projections by identifying less plausible models.

Examining the full ensemble of models, we found that monsoon precipitation change was strongly negatively correlated with SST changes in the western tropical Pacific, and also with local surface temperatures over northern Australia. The strengthening of land-ocean temperature contrasts in CMIP5 models was not found to result in increased monsoon precipitation, but rather there was an inverse relationship between DJF and SON land-ocean temperature contrast changes and DJF precipitation changes. This implies that increased precipitation in some models is driving relative cooling (less warming) over northern Australian land areas. Finally, we investigated whether an increased interhemispheric temperature gradient would enhance cross-equatorial moisture transport from south to north and hence weaken the Australian monsoon. A negative correlation between interhemispheric temperature gradient and Australian monsoon precipitation for the near-tropical 
domain was consistent with this mechanism, but the weak correlation and large model spread implies this is not a dominant driver of Australian monsoon changes in the CMIP5 ensemble.

The 33 CMIP5 models were divided into DRY, MID, and WET terciles based on their projections of future Australian summer monsoon precipitation. The DRY models simulated decreased precipitation over northern Australia and increased precipitation over the WEP, while the WET models simulated increased precipitation over a wider region, including northern Australia and the southwest Pacific. The WET models simulated increased precipitation in the eastern and central equatorial Pacific, but little change in the WEP. The precipitation changes for the two groups of models were consistent with mean surface temperature changes, with the DRY models simulating much greater warming in the WEP than the WET models, and also greater warming over northern Australian land areas. Analysis of the biases in precipitation and temperature for the DRY and WET models indicates that the DRY models have larger biases in SST in the WEP, which is the same region where these models simulate large future warming. This suggests that the projections from the DRY group of models are less robust, as they are driven by changes in a region of large model systematic errors. Hence, our results support lower confidence for projections of reduced monsoon precipitation than for projections of little change or increased monsoon precipitation. When the three models with the largest WEP SST cold biases (CSIRO Mk3.6.0, MIROC-ESM, and MIROC-ESM-CHEM) are excluded, the result is an MMM DJF monsoon precipitation change of $1.1 \% \mathrm{~K}^{-1}$ (compared with $0.4 \% \mathrm{~K}^{-1}$ for the full ensemble). Our results are broadly consistent with Jourdain et al. (2013), who found that the majority of "best models," selected based on mean monsoon precipitation, seasonal cycle, and interannual variability, simulated increased Australian summer monsoon precipitation.

The difference in spatial pattern of surface temperate warming between DRY and WET models (Fig. 8d) includes a positive anomaly (greater warming in the DRY models) in the WEP region, as well as a broader region of positive anomalies in the central and eastern Pacific, somewhat resembling an El Niño response. However, numerous studies have argued that the enhanced equatorial warming exhibited by many coupled climate models is distinct from the El Niño pattern, as it is caused by different mechanisms and has different teleconnections associated with it (e.g., Liu et al. 2005; DiNezio et al. 2009; Xie et al. 2010). Nonetheless, it is possible that the SST warming pattern of individual CMIP5 models may be associated with the model's
ENSO SST variability pattern, for example, because of biases in the location of the edge of the western Pacific warm pool (Brown et al. 2014). The relationship between model SST warming, ENSO variability, and monsoon rainfall projections will be further explored in a future study.

Decomposition of precipitation changes for the full ensemble and the DRY and WET model groups provided further insight into the mechanisms producing the model monsoon precipitation projections. For all model groups, the thermodynamic component of change was the largest, leading to increased precipitation in the monsoon domain. The dynamic component due to mean weakening of the tropical circulation was a slightly smaller negative term, producing a positive residual over northern Australia when these two main terms were added. The opposing sign of total precipitation change in the DRY and WET models was found to be a result of 1) the opposing sign of the spatial shift component, which is negative for DRY models and positive for WET models; 2) the larger negative anomaly due to relative humidity component in DRY models; and 3) the larger negative anomaly due to the nonlinear component in DRY models. These three factors are all important over the land domain examined, but for a larger land plus ocean domain, the spatial shift term dominates the response.

The importance of the spatial shift in convective activity for regional precipitation change is in agreement with studies of mean tropical precipitation (Chadwick et al. 2013) and the West African monsoon (Kent et al. 2015). This result raises the question of what determines the spatial shifts in precipitation. Many studies have identified the role of patterns of SST change in driving precipitation change in the tropics (e.g., Xie et al. 2010; Ma and Xie 2013; Huang et al. 2013). The strong influence of SST warming in the WEP on Australian monsoon precipitation identified in this study is an example of the importance of SST warming patterns for tropical precipitation change. Thus, the role of model SST biases is highlighted, as these are likely to influence the SST warming patterns, as we found for the WEP region. More generally, our results underline the importance of constraining uncertainty in model SST warming patterns in the tropical Pacific. This challenge is beyond the scope of the current study but is fundamental to providing more robust projections of tropical precipitation, including the Australian summer monsoon, in a future warmer climate.

Acknowledgments. The research presented in this paper was supported by the Australian Climate Change Science Programme, jointly funded by the Department 
of the Environment, the Bureau of Meteorology, and CSIRO. We thank Robin Chadwick, Ian Smith, and Hanh Nguyen for useful comments on the manuscript. The comments of two anonymous reviewers also improved the manuscript. We acknowledge the World Climate Research Programme's Working Group on Coupled Modeling, which is responsible for CMIP, and we thank the climate modeling groups (listed in Table 1 of this paper) for producing and making available their model output. For CMIP the U.S. Department of Energy's Program for Climate Model Diagnosis and Intercomparison provides coordinating support and led development of software infrastructure in partnership with the Global Organization for Earth System Science Portals.

\section{REFERENCES}

Adler, R. F., and Coauthors, 2003: The version-2 Global Precipitation Climatology Project (GPCP) monthly precipitation analysis (1979-present). J. Hydrometeor., 4, 1147-1167, doi:10.1175/1525-7541(2003)004<1147:TVGPCP > 2.0.CO;2.

Brown, J. N., and Coauthors, 2013: Implications of CMIP3 model biases and uncertainties for climate projections in the western tropical Pacific. Climatic Change, 119, 147-161, doi:10.1007/ s10584-012-0603-5.

- C. Langlais, and C. Maes, 2014: Zonal structure and variability of the western Pacific dynamic warm pool edge in CMIP5. Climate Dyn., 42, 3061-3076, doi:10.1007/s00382-013-1931-5.

Brown, J. R., A. F. Moise, and R. A. Colman, 2013: The South Pacific Convergence Zone in CMIP5 simulations of historical and future climate. Climate Dyn., 41, 2179-2197, doi:10.1007/ s00382-012-1591-x.

Chadwick, R., I. Boutle, and G. Martin, 2013: Spatial patterns of precipitation change in CMIP5: Why the rich do not get richer in the tropics. J. Climate, 26, 3803-3822, doi:10.1175/ JCLI-D-12-00543.1.

Chou, C., J. D. Neelin, C.-A. Chen, and J.-Y. Tu, 2009: Evaluating the "rich-get-richer" mechanism in tropical precipitation change under global warming. J. Climate, 22, 1982-2005, doi:10.1175/2008JCLI2471.1.

Christensen, J. H., and Coauthors, 2013: Climate phenomena and their relevance for future regional climate change. Climate Change 2013: The Physical Science Basis, T. F. Stocker et al., Eds., Cambridge University Press, 1217-1308.

Collins, M., and Coauthors, 2010: The impact of global warming on the tropical Pacific Ocean and El Niño. Nat. Geosci., 3, 391397, doi:10.1038/ngeo868

Colman, R. A., A. F. Moise, and L. I. Hanson, 2011: Tropical Australian climate and the Australian monsoon as simulated by 23 CMIP3 models. J. Geophys. Res., 116, D10116, doi:10.1029/2010JD015149.

Dai, A., H. Li, Y. Sun, L.-C. Hong, LinHo, C. Chou, and T. Zhou, 2013: The relative roles of upper and lower tropospheric thermal contrasts and tropical influences in driving Asian summer monsoons. J. Geophys. Res. Atmos., 118, 7024-7045, doi:10.1002/jgrd.50565.

DiNezio, P. N., A. C. Clement, G. A. Vecchi, B. J. Soden, B. P. Kirtman, and S.-K. Lee, 2009: Climate response of the equatorial Pacific to global warming. J. Climate, 22, 4873-4892, doi:10.1175/2009JCLI2982.1.
Drosdowsky, W., 1996: Variability of the Australian summer monsoon at Darwin: 1957-1992. J. Climate, 9, 85-96, doi:10.1175/ 1520-0442(1996)009<0085:VOTASM >2.0.CO;2.

Emori, S., and S. J. Brown, 2005: Dynamic and thermodynamic changes in mean and extreme precipitation under changed climate. Geophys. Res. Lett., 32, L17706, doi:10.1029/ 2005GL023272.

Endo, H., and A. Kitoh, 2014: Thermodynamic and dynamic effects on regional monsoon rainfall changes in a warmer climate. Geophys. Res. Lett., 41, 1704-1710, doi:10.1002/2013GL059158.

Grose, M. R., and Coauthors, 2014a: Assessment of the CMIP5 global climate model simulations of the western tropical Pacific climate system and comparison to CMIP3. Int. J. Climatol., 34, 3382-3399, doi:10.1002/joc.3916.

_ J. Bhend, S. Narsey, A. Sen Gupta, and J. R. Brown, 2014b: Can we constrain CMIP5 rainfall projections in the tropical Pacific based on surface warming patterns? J. Climate, 27, 9123-9138, doi:10.1175/JCLI-D-14-00190.1.

Held, I. M., and B. J. Soden, 2006: Robust responses of the hydrological cycle to global warming. J. Climate, 19, 5686-5699, doi:10.1175/JCLI3990.1.

Hsu, P.-C., T. Li, H. Murakami, and A. Kitoh, 2013: Future change of the global monsoon revealed from 19 CMIP5 models. J. Geophys. Res. Atmos., 118, 1247-1260, doi:10.1002/ jgrd.50145.

Huang, P., S.-P. Xie, K. Hu, G. Huang, and R. Huang, 2013: Patterns of the seasonal response of tropical rainfall to global warming. Nat. Geosci., 6, 357-361, doi:10.1038/ngeo1792.

Jones, D. A., W. Wang, and R. Fawcett, 2009: High-quality spatial climate data-sets for Australia. Aust. Meteor. Oceanogr. J., 58, 233-248.

Jourdain, N. C., A. Sen Gupta, A. S. Taschetto, C. C. Ummenhofer, A. F. Moise, and K. Ashok, 2013: The Indo-Australian monsoon and its relationship to ENSO and IOD in reanalysis data and the CMIP3/CMIP5 simulations. Climate Dyn., 41, 30733102, doi:10.1007/s00382-013-1676-1.

Kanamitsu, M., W. Ebisuzaki, J. Woollen, S.-K. Yang, J. J. Hnilo, M. Fiorino, and G. L. Potter, 2002: NCEP-DOE AMIP-II Reanalysis (R-2). Bull. Amer. Meteor. Soc., 83, 1631-1643, doi:10.1175/BAMS-83-11-1631.

Kent, C., R. Chadwick, and D. P. Rowell, 2015: Understanding uncertainties in future projections of seasonal tropical precipitation. J. Climate, 28, 4390-4413, doi:10.1175/JCLI-D-14-00613.1.

Kitoh, A., H. Endo, K. Krishna Kumar, I. F. A. Cavalcanti, P. Goswami, and T. Zhou, 2013: Monsoons in a changing world: A regional perspective in a global context. J. Geophys. Res. Atmos., 118, 3053-3065, doi:10.1002/jgrd.50258.

Lee, J.-Y., and B. Wang, 2014: Future change of global monsoons in the CMIP5. Climate Dyn., 42, 101-119, doi:10.1007/ s00382-012-1564-0.

Li, G., and S.-P. Xie, 2014: Tropical biases in the CMIP5 multimodel ensemble: The excessive equatorial Pacific cold tongue and double ITCZ problems. J. Climate, 27, 1765-1780, doi:10.1175/JCLI-D-13-00337.1.

Li, Y., N. C. Jourdain, A. S. Taschetto, C. C. Ummenhofer, K. Ashok, and A. Sen Gupta, 2012: Evaluation of monsoon seasonality and the tropospheric biennial oscillation transitions in the CMIP models. Geophys. Res. Lett., 39, L20713, doi:10.1029/2012GL053322.

Liu, Z., S. Vavrus, F. He, N. Wen, and Y. Zhong, 2005: Rethinking tropical ocean response to global warming: The enhanced equatorial warming. J. Climate, 18, 4684-4700, doi:10.1175/ JCLI3579.1. 
Ma, J., and S.-P. Xie, 2013: Regional patterns of sea surface temperature change: A source of uncertainty in future projections of precipitation and atmospheric circulation. J. Climate, 26, 2482-2501, doi:10.1175/JCLI-D-12-00283.1.

Meehl, G. A., C. Covey, T. Delworth, M. Latif, B. McAvaney, J. F. B. Mitchell, R. J. Stouffer, and K. E. Taylor, 2007: The WCRP CMIP3 multimodel dataset: A new era in climate change research. Bull. Amer. Meteor. Soc., 88, 1383-1394, doi:10.1175/BAMS-88-9-1383.

Moise, A. F., R. A. Colman, and J. R. Brown, 2012: Behind uncertainties in projections of Australian tropical climate: Analysis of 19 CMIP3 models. J. Geophys. Res., 117, D10103, doi:10.1029/2011JD017365.

Power, S., F. Tseitkin, S. Torok, B. Lavery, and B. McAvaney, 1998: Australian temperature, Australian rainfall, and the Southern Oscillation, 1910-1996: Coherent variability and recent changes. Aust. Meteor. Mag., 47, 85-101.

Rayner, N. A., D. E. Parker, E. B. Horton, C. K. Folland, L. V. Alexander, D. P. Rowell, E. C. Kent, and A. Kaplan, 2003: Global analyses of sea surface temperature, sea ice, and night marine air temperature since the late nineteenth century. J. Geophys. Res., 108, 4407, doi:10.1029/2002JD002670.

Seager, R., N. Naik, and G. Vecchi, 2010: Thermodynamic and dynamic mechanisms for large-scale changes in the hydrological cycle in response to global warming. J. Climate, 23, 4651-4668, doi:10.1175/2010JCLI3655.1.

Smith, I. N., L. Wilson, and R. Suppiah, 2008: Characteristics of the northern Australian rainy season. J. Climate, 21, 4298-4311, doi:10.1175/2008JCLI2109.1.

Sun, Y., Y. Ding, and A. Dai, 2010: Changing links between South Asian summer monsoon circulation and tropospheric land-sea thermal contrasts under a warming scenario. Geophys. Res. Lett., 37, L02704, doi:10.1029/2009GL041662.

Taylor, K. E., R. J. Stouffer, and G. A. Meehl, 2012: An overview of CMIP5 and the experiment design. Bull. Amer. Meteor. Soc., 93, 485-498, doi:10.1175/BAMS-D-11-00094.1.

Uppala, S. M., and Coauthors, 2005: The ERA-40 Reanalysis. Quart. J. Roy. Meteor. Soc., 131, 2961-3012, doi:10.1256/qj.04.176.
Vecchi, G. A., B. J. Soden, A. T. Wittenberg, I. M. Held, A. Leetmaa, and M. J. Harrison, 2006: Weakening of tropical Pacific atmospheric circulation due to anthropogenic forcing. Nature, 441, 73-76, doi:10.1038/nature04744.

Wang, B., J. Liu, H.-J. Kim, P. J. Webster, and S.-Y. Yim, 2012: Recent change of the global monsoon precipitation (1979-2008). Climate Dyn., 39, 1123-1135, doi:10.1007/s00382-011-1266-z.

— - S.-Y. Yim, J.-Y. Lee, J. Liu, and K.-J. Ha, 2014: Future change of Asian-Australian monsoon under RCP4.5 anthropogenic warming scenario. Climate Dyn., 42, 83-100, doi:10.1007/ s00382-013-1769-x.

Wardle, R., and I. Smith, 2004: Modeled response of the Australian monsoon to changes in land surface temperatures. Geophys. Res. Lett., 31, L16205, doi:10.1029/2004GL020157.

Watterson, I. G., 2012: Understanding and partitioning future climates for Australian regions from CMIP3 using ocean warming indices. Climatic Change, 111, 903-922, doi:10.1007/ s10584-011-0166-x.

Xie, P., and P. A. Arkin, 1997: Global precipitation: A 17-year monthly analysis based on gauge observations, satellite estimates, and numerical model outputs. Bull. Amer. Meteor. Soc., 78, 2539-2558, doi:10.1175/1520-0477(1997)078<2539: GPAYMA $>2.0 . \mathrm{CO} ; 2$.

Xie, S.-P., C. Deser, G. A. Vecchi, J. Ma, H. Teng, and A. T. Wittenberg, 2010: Global warming pattern formation: Sea surface temperature and rainfall. J. Climate, 23, 966-986, doi:10.1175/2009JCLI3329.1.

Zhang, H., 2010: Diagnosing Australia-Asian monsoon onset/ retreat using large-scale wind and moisture indices. Climate Dyn., 35, 601-618, doi:10.1007/s00382-009-0620-x.

— A. Moise, P. Liang, and L. Hanson, 2013: The response of summer monsoon onset/retreat in Sumatra-Java and tropical Australia region to global warming in CMIP3 models. Climate Dyn., 40, 377-399, doi:10.1007/s00382-012-1389-x.

, G. Dong, A. Moise, R. Colman, L. Hanson, and H. Ye, 2016: Uncertainty in CMIP5 model-projected changes in the onset/ retreat of the Australian summer monsoon. Climate Dyn., 46, 2371-2389, doi:10.1007/s00382-015-2707-x. 